2022, Instituto Mexicano de Tecnología del Agua

Tecnología y

Ciencias $₫$ Agua
Open Access bajo la licencia CC BY-NC-SA 4.0 (https://creativecommons.org/licenses/by-nc$\mathrm{sa} / 4.0 /)$

DOI: $10.24850 / j-$ tyca-2022-01-03

Artículos

\title{
Evaluación de la operación de un tramo del canal principal de riego con un enfoque económico
}

\section{Evaluation of the operation in a main canal reach of an irrigation district with an economic approach}

Penélope Cruz-Mayo ${ }^{1}$, ORCID: https://orcid.org/0000-0001-9982-5659

Ariosto Aguilar², ORCID: https://orcid.org/0000-0002-2884-5908

1Posgrado en Ingeniería, Universidad Nacional Autónoma de México, Campus Morelos IMTA, Jiutepec, Morelos, México, penelopecruz@comunidad.unam.mx

2Subcoordinador de Posgrado, Instituto Mexicano de Tecnología del Agua, Jiutepec, Morelos, México, aaguilar@tlaloc.imta.mx

Autora para correspondencia: Penélope Cruz-Mayo, penelopecruz@comunidad.unam.mx

\section{Resumen}

En un distrito de riego, la red de distribución del agua es un punto esencial en el manejo y la entrega de agua a los usuarios. En el diseño de un nuevo distrito de riego se establece la forma de manejo, y se aplican 
2022, Instituto Mexicano de Tecnología del Agua

Tecnología y

Ciencias $\stackrel{\Xi}{\unlhd}$ gua
Open Access bajo la licencia CC BY-NC-SA 4.0 (https://creativecommons.org/licenses/by-nc$\mathrm{sa} / 4.0 /)$

herramientas y métodos específicos para lograrla; en cambio, si el distrito ya está construido y en operación, para mejorar el uso del agua se desarrolla un proyecto de modernización que debe tomar en cuenta los aspectos de ingeniería y sociales de la zona. En este trabajo se presenta una análisis económico e hidráulico para implementar un modelo de control automático de las compuertas de un distrito de riego. E funcionamiento hidráulico de la red de canales se analiza con un modelo de simulación numérica, con diferentes opciones de control automático que se pueden instaurar, y un análisis de los precios sombra en la producción agrícola a partir de los escenarios dinámicos de simulación numérica. Esta metodología se aplica a un distrito de riego ubicado en el noroeste de México y se obtienen diferentes escenarios que pueden ser considerados en la modernización de la red de canales.

Palabras clave: control automático, simulación numérica de flujo en canales de riego, valor del agua de riego.

\section{Abstract}

In an irrigation district, the water distribution network is an essential point in the management and delivery of water to users. In the design of a new irrigation district, the way of management is established, and specific tools and methods are applied to achieve it. In contrast, if the district is already built and in operation, to improve the use of water, a modernization project is developed that must consider the engineering and social aspects of the area. In this work, an economic and hydraulic analysis is presented to implement an automatic control model of the gates in an irrigation district. The hydraulic operation of the canal network 
2022, Instituto Mexicano de Tecnología del Agua

Tecnología y

Ciencias $\stackrel{\unlhd}{\triangleleft}$ gua
Open Access bajo la licencia CC BY-NC-SA 4.0 (https://creativecommons.org/licenses/by-nc$\mathrm{sa} / 4.0 /)$

is analyzed with a numerical simulation model, with different automatic control options that can be established, and an analysis of the shadow prices in agricultural production based on dynamic numerical simulation scenarios. This methodology is applied to an irrigation district located in the northwest of Mexico and different scenarios are obtained that can be considered in the modernization of the canal network.

Keywords: Automatic control, numerical simulation of irrigation channels, irrigation water value.

Recibido: 20/07/2020

Aceptado: 02/12/2020

\section{Introducción}

En el diseño de una red canales se tiene en cuenta que la eficiencia de operación depende de la técnica de regulación y la forma de operar las compuertas de regulación. Cuando el diseño es nuevo, se definen la operación y el control con estructuras para tener un sistema altamente eficiente. Sin embargo, estas condiciones de diseño no son las más usuales, porque en muchos países los distritos de riego y las redes de 
2022, Instituto Mexicano de Tecnología del Agua

Tecnología y

Ciencias $\stackrel{\Xi}{\unlhd}$ gua
Open Access bajo la licencia CC BY-NC-SA 4.0 (https://creativecommons.org/licenses/by-nc$\mathrm{sa} / 4.0 /)$

canales ya están operando y modificar la forma de regulación tiene un alto costo.

La necesidad de un uso más racional del agua y las competencias en la demanda de agua - como la necesidad de cubrir los requerimientos de uso urbano por el crecimiento poblacional o el aumento del valor del agua destinada al uso industrial-implican evaluar si es factible modernizar los sistemas de regulación del agua de riego en distrito. En el caso particular de los canales de riego, una opción recurrente es automatizar las compuertas con el mismo tipo de regulación.

Los estudios sobre proyectos de automatización como el de Clemmens, Sloan y Schuurmans (1994) no indican con claridad la rentabilidad de estas acciones, pero sí indican que los volúmenes ahorrados son una oferta de mejora en el manejo del agua. Ahora bien, los resultados de estas estrategias de modernización no siempre han logrado los objetivos planteados en el proceso de diseño. Por ejemplo, tras la instalación de compuertas auto operantes tipo AMIL en canales ya construidos (Pedroza \& Hinojosa, 2014; García, 2015), se han observado problemas de vandalismo, dificultad en la calibración de las estructuras $y$, en algunos casos, oscilaciones continuas de la compuerta.

Entre los esfuerzos por mejorar la operación de los canales se incluyen las obras de control automático, por ejemplo, en el Canal Alto del Río Yaqui (Aguilar-Chávez, Pedroza-González, Kosuth, \& Daval, 1994) y en el Canal Principal La Begoña (González Trinidad, León-Mojarro, Carmona-Ruiz, \& Rendón-Pimentel, 1999). El resultado obtenido en la implementación de estos proyectos fue un buen diseño e instalación de sistemas control automático, pero no fue posible convencer a los 
2022, Instituto Mexicano de Tecnología del Agua

Tecnología y

Ciencias đgua
Open Access bajo la licencia CC BY-NC-SA 4.0 (https://creativecommons.org/licenses/by-nc$\mathrm{sa} / 4.0 /)$

operarios y usuarios de los beneficios que se obtendrían al utilizar estos sistemas. En el caso de los operarios es más complicado debido a que tienen una gran experiencia en el control y regulación manual, y los efectos de la automatización no se perciben en forma directa, pues no tienen registros continuos de las entregas de volúmenes sino sólo verificaciones esporádicas.

Respecto a la apropiación de las nuevas tecnologías, Van-Overloop et al. (2014) consideran que para automatizar un canal no se debe eliminar totalmente la participación del ser humano en su operación, por lo que proponen añadir una estrategia de control manual al modelo de control automático (MPC, por sus siglas en inglés) para tener un control combinado MoMPC (Mobile Model Predictive Control). Este tipo de control es más aceptado, porque permite incorporar los conocimientos del operario manual (Van-Overloop et al., 2014).

Por su parte, Hashemy, Hasani, Majidi y Maestre (2016), y Hassani et al. (2019) proponen operar un canal principal desde una perspectiva económica, donde el objetivo es optimizar la asignación del agua para maximizar el ingreso económico derivado de las actividades agrícolas. Este marco de operación incluye un modelo económico alimentado por los costos de producción, el rendimiento de los cultivos, las tarifas del agua, los precios de venta de los cultivos, la disponibilidad del agua, las concesiones, los requerimientos de riego, las eficiencias, etcétera, con el objetivo de maximizar las ganancias del distrito de riego. Además, se proponen esquemas de distribución del agua a las unidades agrícolas con base en el promedio ponderado del valor económico del agua. Para la aplicación de esta estrategia, Hassani et al. (2019) utilizan un modelo de 
2022, Instituto Mexicano de Tecnología del Agua

Tecnología y

Ciencias $\stackrel{\Xi}{\Im}$ Agua
Open Access bajo la licencia CC BY-NC-SA 4.0 (https://creativecommons.org/licenses/by-nc$\mathrm{sa} / 4.0 /$ )

simulación de la operación y evalúan la reasignación de los volúmenes de agua. Los resultados maximizan la ganancia global del distrito de riego cuidando la asignación de los cultivos más rentables.

En un proyecto de automatización de canales de riego es necesario encontrar un punto de equilibrio en el que se consideren los beneficios que pueden tener los usuarios, en este caso los productores, y un manejo más sustentable del recurso. Así, es importante tener en cuenta las asimetrías entre los usuarios, considerando su ubicación a lo largo del canal, pues los volúmenes y tiempos de entrega de agua se cumplen con mayor certidumbre a los usuarios aguas arriba y va disminuyendo la eficiencia hacia aguas abajo.

En algunos países, en el proceso de producción agrícola se considera que el elemento esencial hídrico tiene un costo que se evalúa como un insumo e impacta en la producción, acción que tiene un beneficio directo ante cualquier acción de modernización; pero existen otros escenarios en donde el costo del agua no tiene un valor económico, por ejemplo, en México, donde la ley indica que el uso de agua para la agricultura está exento de pago de cuota de acuerdo con el artículo 224 fracción IV de la Ley Federal de Derechos (1981). Este aspecto de no cobro sobre el uso de agua agrícola no refleja en forma directa la importancia del valor del agua como un recurso en la producción, pero no resta que pueda analizarse de otra forma.

De acuerdo con la experiencia del Banco Mundial en Bangladesh y en Nepal, "Ios usuarios pobres están dispuesto a pagar más por el agua siempre y cuando el sistema sea de calidad y confiable" (Norton, 2004). El punto de confiabilidad es un valor adicional que se debe considerar en 
2022, Instituto Mexicano de Tecnología del Agua (https://creativecommons.org/licenses/by-nc$\mathrm{sa} / 4.0 /$ )

cualquier estudio de mejoramiento en la operación de un canal de riego. Por lo tanto, para analizar con un enfoque sociohidráulico la implementación de un proyecto de automatización de canales, se deben tener las características del proyecto de ingeniería, las opciones de hidráulica y de automatización electrónica o fluídica, pero además contar con un análisis detallado del impacto de beneficio social y económico del proyecto.

En este trabajo, además de los aspectos de ingeniería, se propone evaluar dinámicamente los volúmenes entregados a cada toma y los impactos en la producción. Por ejemplo, se puede entregar el volumen global, pero con variaciones en el gasto suministrado durante el día o que la programación de una toma adicional cercana produzca disminuciones en el volumen. Para evaluar los impactos de estas variaciones en las entregas de agua a cada usuario, se analizarán éstas en función del precio sombra de los cultivos en la zona. Con este análisis se busca identificar el valor social y ambiental del agua, comparado con el proceso de producción de los cultivos.

La idea de aplicar un indicador económico al evaluar el desempeño del control de canales tiene antecedentes como el trabajo de Álvarez, Ridao, Ramírez y Sánchez (2013), en el que se evaluó el desempeño de un modelo de control predictivo descentralizado en el canal de riego "La Pedrera" en Murcia, España. En dicha evaluación se utilizó un índice económico para penalizar con $0.2 € / \mathrm{m}^{3}$ el volumen de agua desperdiciada y con $0.5 € / \mathrm{m}^{3}$ la demanda insatisfecha. Respecto al monto de las penalizaciones, Ramírez (2018) comenta que: "se eligieron de manera que fuesen números razonables y diferentes entre sí, a fin de señalar que 
Teçnología y

Ciencias $₫$ Agua
2022, Instituto Mexicano de Tecnología del Agua Open Access bajo la licencia CC BY-NC-SA 4.0 (https://creativecommons.org/licenses/by-nc$\mathrm{sa} / 4.0 /$ )

no son igualmente tolerables las condiciones de demanda insatisfecha o de pérdida de agua". En la Figura 1 se muestran las variaciones típicas del suministro de gastos, y se distingue entre entregas excedentes y faltantes con respecto al gasto esperado.

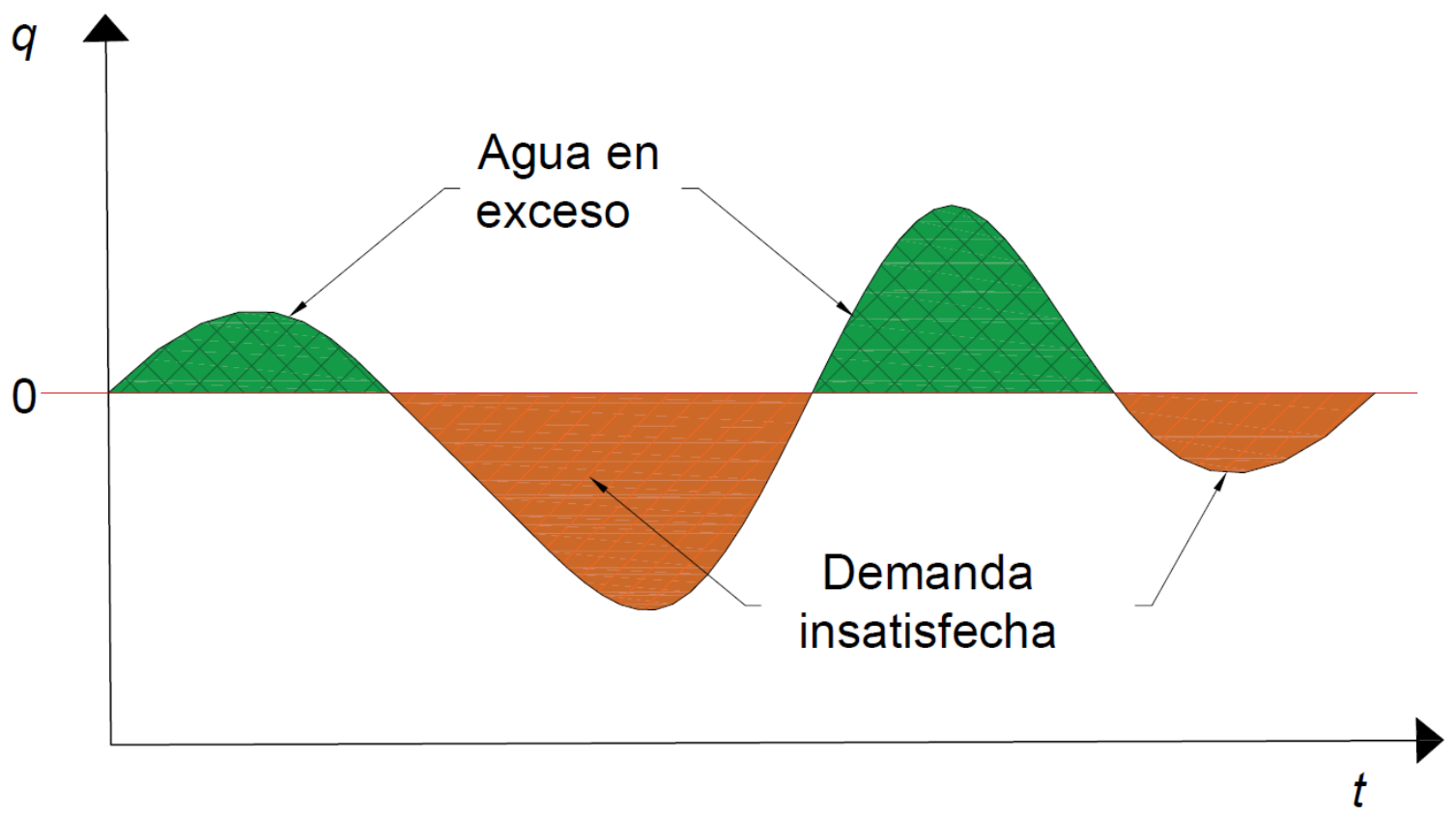

Figura 1. Errores en el tránsito de un incremento de gasto. Se distingue entre demanda insatisfecha y en exceso, y se aplica un indicador financiero para evaluar el desempeño de un controlador predictivo descentralizado. Basado en Álvarez et al. (2013). 
2022, Instituto Mexicano de Tecnología del Agua

Tecnología y

Ciencias $\stackrel{\unlhd}{\simeq}$ gua
Open Access bajo la licencia CC BY-NC-SA 4.0 (https://creativecommons.org/licenses/by-nc$\mathrm{sa} / 4.0 /$ )

\section{Aspectos económicos e hidráulicos en la operación de canales en distritos de riego}

Los estudios de funcionamiento hidráulico de una red de canales se fundamentan en los controles de gasto circulante y volúmenes entregados en las tomas laterales. En este trabajo se propone una metodología que toma en cuenta los aspectos de la ingeniera (hidráulica y de operación de estructuras), y los puntos relacionados con la aceptación social de las mejoras y los impactos en la economía, pero que a su vez busca un marco ambientalmente sustentable. En la Figura 2 se muestra un mapa conceptual que involucra los aspectos que se pueden analizar. 
2022, Instituto Mexicano de Tecnología del Agua

Tecnología y

Ciencias $₫$ Agua
Open Access bajo la licencia CC BY-NC-SA 4.0 (https://creativecommons.org/licenses/by-nc$\mathrm{sa} / 4.0 /)$

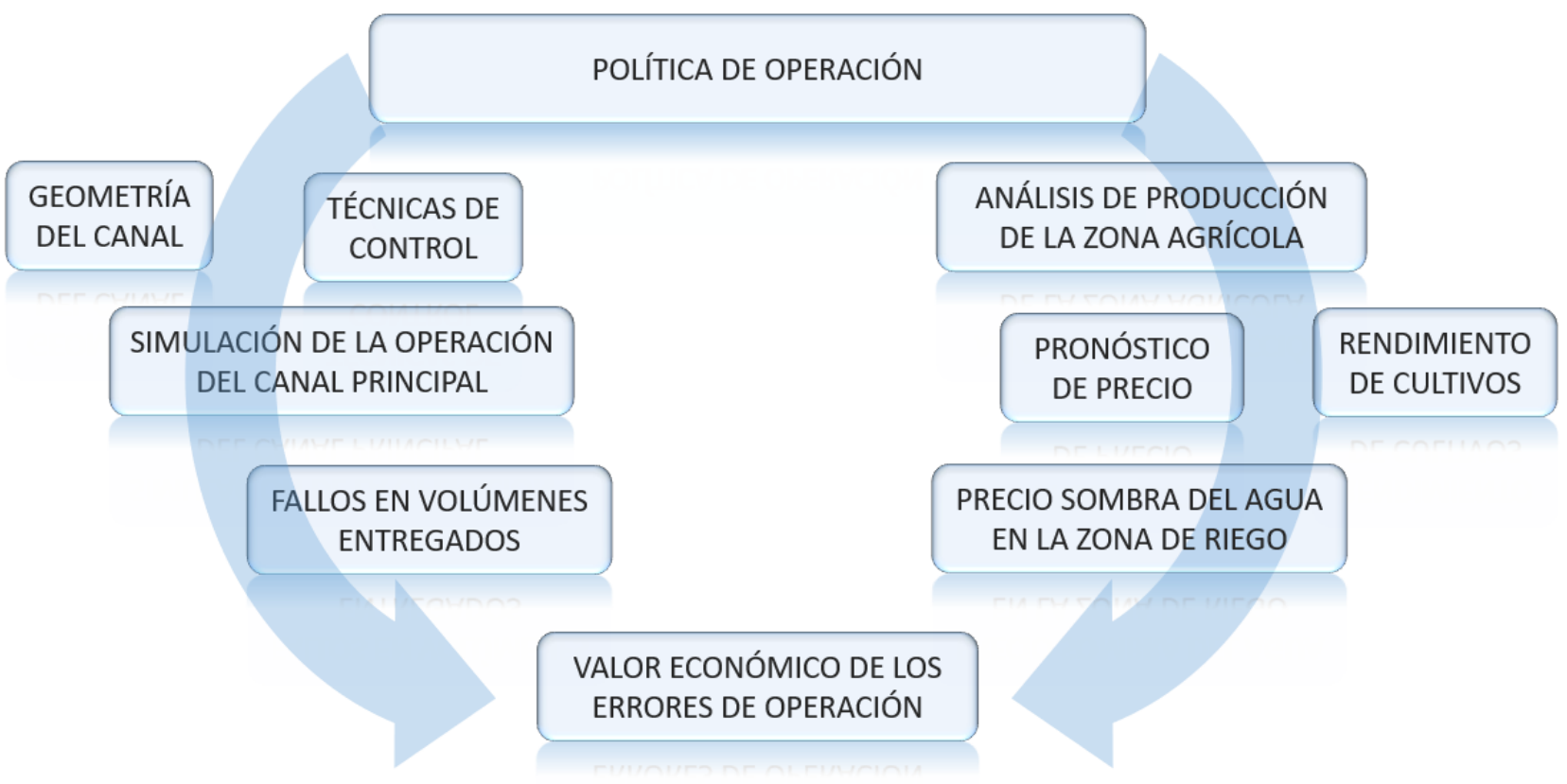

Figura 2. Mapa conceptual de operación integral de los canales de riego. Se muestra la interacción entre los aspectos técnicos de la operación de canales y los económicos de la zona agrícola. El valor económico de los errores en la operación es el reflejo de la eficiencia de las técnicas de control ante las condiciones específicas de mercado, rendimiento de cultivos y disponibilidad hídrica de una zona de cultivo.

A la izquierda del esquema de la Figura 2 se muestran los factores que influyen directamente en el funcionamiento hidráulico de la operación del canal y a la derecha los factores sociales. El funcionamiento hidráulico obedece a la necesidades sociales del sitio.

Una obra de ingeniería busca satisfaceruna necesidad social. En los casos más ortodoxos se trata de instalar las compuertas de regulación 
2022, Instituto Mexicano de Tecnología del Agua

para que puedan ser operadas de forma manual. En contraparte, cualquier acción de mejora que se proponga, como la automatización de la compuertas y los tipos de algoritmos con los que se maneja la operación, debe ser evaluada no sólo en la respuesta del control local, sino en forma global. En ese sentido, esta metodología se enfoca en medir el impacto que genera una técnica de operación y control. El punto de partida es analizar la política de operación generada por los requerimentos de riego en los puntos de entrega localizados a lo largo del canal.

Con lo anterior se genera un escenario de operación que se prueba en un modelo de simulación cargado con anterioridad con la topología del canal. Los resultados de simulación presentan de forma dinámica la confiabilidad en las entregas de los gastos a los usuarios. En forma ideal no debería haber ninguna diferencia entre la demanda y la entrega, pero en la realidad hay discordancias denominadas fallos. Con estos valores se realizará el análisis económico, considerando la zona de cultivo, el requerimiento hídrico y los precios en el mercado. Para evaluar los fallos se plantean tres formas: a) el precio sombra del maíz; b) el precio de la operación del distrito de riego, y c) la productividad de la zona de riego.

El precio sombra del agua representa el valor en que se incrementaría el ingreso neto si se dispusiera de una unidad adicional de agua (Zetina-Espinosa, Mora-Flores, Martínez-Damián, Cruz-Jiménez, \& Téllez-Delgado, 2013). El precio de la operación del distrito de riego es el mínimo con el que el distrito de riego alcanzaría a cubrir todos sus gastos de operación (Torres-Sombra \& García, 2015). La productividad de la zona se refiere a la relación entre cada metro cúbico de agua requerido y 
2022, Instituto Mexicano de Tecnología del Agua

Tecnología y

Ciencias $₫$ Agua
Open Access bajo la licencia CC BY-NC-SA 4.0 (https://creativecommons.org/licenses/by-nc$\mathrm{sa} / 4.0 /)$

el precio medio rural (PMR) estimado con un proyección de precios de mercado a futuro. Debido a que las zonas de riego tienen diferentes niveles de productividad y de disponibilidad de agua, se propone analizar para cada caso los cultivos de la zona, lo que involucra su consumo de agua, rendimientos, costos de producción y precios al mercado.

\section{Escenarios de operación de un canal de riego}

Para determinar con certidumbre los volúmenes circulantes y entregados en cada punto de extracción del canal, fue necesario adecuar un modelo numérico que resolviera la dinámica del flujo circulante y las condiciones de frontera de las estructuras de control y regulación, así como evaluar los gastos que entregaban en cada toma lateral. Se uso el modelo SFT (Sistema de Flujo Transitorio en canales de riego) (Cruz-Mayo, AguilarChavez, \& De-la-Torre, 2019); resuelve las ecuaciones de Saint-Venant en su versión conservativa (Abbot, 1979), que incluye los gastos laterales y los cambios de sección.

El SFT es un modelo en diferencias finitas no lineal (Aldama \& Aguilar, 1996), con un acoplamiento de las condiciones de frontera para las compuertas de regulación, que permite generar un modelo multitramo (Cruz-Mayo et al., 2019). Además del modelo numérico de solución de las 
Tecnología y

Ciencias $\stackrel{\unlhd}{\unlhd}$ gua
2022, Instituto Mexicano de Tecnología del Agua

Open Access bajo la licencia CC BY-NC-SA 4.0 (https://creativecommons.org/licenses/by-nc$\mathrm{sa} / 4.0 /$ )

ecuaciones de flujo, el SFT permite hacer un monitoreo de los niveles y gastos en diferentes puntos del canal, y ejecutar de forma paralela un modelo de control de las aperturas de las compuertas.

\section{Operación de canales}

El objetivo del control de canales es proveer a cada usuario de los volúmenes requeridos en el momento correcto, reducir las pérdidas tanto como sea posible, proteger la infraestructura (Malaterre, 2007) y disminuir las fluctuaciones en los gastos entregados. No cumplir lo anterior afecta la confiabilidad del sistema de distribución del agua, sobre todo para los usuarios que se ubican en la cola del canal (Clemmens et al., 1994). La parte física del sistema para analizar las estrategias de control es la red de canales. En este caso se plantea un escenario de operación y se utilizarán modelos de control con diferentes propuestas metodológicas que se analizan con el modelo SFT.

De acuerdo con Hashemy y Roozbhani (2015), al elegir el tipo de control en el canal principal se deben utilizar criterios que cubran los aspectos técnicos, económicos y sociales adecuados al lugar de estudio. Los criterios técnicos tienen el propósito de evaluar el método de operación, al controlar los niveles y gastos de descarga. El criterio económico se refiere a los costos de implementarla técnica de operación 
2022, Instituto Mexicano de Tecnología del Agua

Tecnología y

Ciencias ฐึgua
Open Access bajo la licencia CC BY-NC-SA 4.0 (https://creativecommons.org/licenses/by-nc$\mathrm{sa} / 4.0 /$ )

(sensores, data loggers, actuadores automáticos, etc.). Los aspectos sociales se refieren a la disposición de los usuarios a operar, cuidar los equipos, y a cuestiones de seguridad de las instalaciones para mitigar el vandalismo.

En este trabajo se tomó en cuenta la condición de que la mayoría de los canales principales en México operan con control aguas arriba de las estructuras de regulación y, por lo tanto, se requiere tener un nivel constante para proporcionar una derivación constante de gasto a los canales secundarios. Esta condición es el punto de evaluación principal de los volúmenes requeridos por los usuarios.

\section{Métodos de control de compuertas analizados}

\section{Control por retardos}

El operador de canales de riego elabora los calendarios de riego con base en los volúmenes previamente solicitados por los usuarios. Así, se conoce con anticipación día, hora y volumen a entregar en cada toma. A continuación se describe el algoritmo de control manual basado en el retardo de una onda al cruzar el canal, que se estima como: 
2022, Instituto Mexicano de Tecnología del Agua

Tecnología y

Ciencias $\stackrel{\unlhd}{\unlhd}$ gua
Open Access bajo la licencia CC BY-NC-SA 4.0 (https://creativecommons.org/licenses/by-nc$\mathrm{sa} / 4.0 /)$

$\Delta T_{m, i}=L_{i} / U_{i}$

donde $\Delta T_{m, i}$ es el retardo en la $i$ - ésima estructura del canal para un gasto $\left(Q_{m}\right) m$-ésimo establecido al inicio del canal (condición dinámica de operación del control manual); $L_{i}$, la distancia entre la cabeza del canal y la estructura de control, y $U_{i}$ es la velocidad absoluta en el tramo agua arriba de la compuerta.

Con la condición de gasto circulante en el tramo se determinan las aperturas $\left(w_{i}\right)$ con la ley de descarga de la compuerta, a partir de las condiciones del perfil de flujo gradualmente variado simulado ante cada condición de gasto $\left(Q_{m}\right)$ previsto y nivel de operación $\left(y_{f}\right)$.

La velocidad absoluta $\left(U_{i}\right)$ depende de la velocidad media $u_{i}\left(A_{J}^{0}\right)$ y la celeridad de onda $\left(\sqrt{g D_{J}^{0}}\right)$ con que una onda cruza cada tramo $i$ (Chaudhry, 2008), y se calcula con la expresión siguiente:

$U_{i}=u_{i}+\sqrt{g D_{J}^{0}}$

En el cálculo de $u_{i}$ y $c_{i}$ se considera el área $A_{J}^{0}$ y $D_{J}^{0}$ de la condición inicial, pues se busca que no existan variaciones en el nivel de operación.

Finalmente, se calcula la hora $H_{m}$ de accionamiento de las compuertas, con los valores acumulados de los retardos $\Delta T_{m, i}$. Este método está precargado en el SFT. Algunas de las limitaciones del método 
2022, Instituto Mexicano de Tecnología del Agua

Tecnología y

Ciencias $\stackrel{\unlhd}{\unlhd}$ Agua
Open Access bajo la licencia CC BY-NC-SA 4.0 (https://creativecommons.org/licenses/by-nc$\mathrm{sa} / 4.0 /$ )

son que no toma en cuenta las extracciones inesperadas, no se evalúa el retardo inducido por alguna operación, y depende de la puntualidad y habilidad del operador de canales para hacer las aperturas y cierres de compuertas.

\section{Control por balance de masa}

Esta estrategia de control global consiste en contabilizar cada determinado tiempo los errores cometidos en las entregas de agua y aplicar una compensación en un periodo que establezca el operario. En el caso de este estudio, la estrategia de control de balance de masa se aplicó con la siguiente secuencia metodológica:

1. Se detecta una extracción aguas abajo del tramo $n$.

2. Se activa durante 30 minutos un control local.

3. Se calcula un balance de masa y se programa la compensación del volumen durante los siguientes 20 minutos.

4. Los siguientes 10 minutos se busca estabilizar el flujo, por lo que no se mueven las compuertas.

5. Finalmente, se hacen las ultimas correcciones con el control local en el nivel de operación. 
2022, Instituto Mexicano de Tecnología del Agua

Tecnología y

Ciencias $₫$ Agua
Open Access bajo la licencia CC BY-NC-SA 4.0 (https://creativecommons.org/licenses/by-nc$\mathrm{sa} / 4.0 /)$

La compensación del volumen es global y se aplica de forma proporcional por tramos, estableciendo en la compuerta aguas arriba el volumen faltante y la apertura de compuerta.

\section{Control local generado con técnicas de perturbación (perturbatorios)}

Si el objetivo del control es mantener constantes en el tiempo el nivel de operación $\bar{y}_{r}$ y un gasto de descarga $Q$ conocido, en este caso se considera que los únicos valores dinámicos del sistema son la apertura de compuerta $w\left(y_{3}, y_{r} ; t\right)$, tirante aguas abajo $y_{3}(t)$ y tirante aguas arriba $y_{r}(t)$. Mediante una expansión en serie de Frechet-Taylor (Milne, 1980) se expresó la apertura y el tirante aguas arriba en función del tirante objetivo y las posibles perturbaciones en la descarga de una compuerta. Así, la apertura de la compuerta se evalúa con el modelo (3) (ver apéndice A):

$w^{n+1}=w^{n}+K_{L} K_{p_{1}} y_{r}^{\prime}$

en donde $w^{n}$ es la apertura de compuerta actual y $w^{n+1}$ la actualización; $F_{1}$ contiene los términos invariantes de la descarga $F_{1}=\frac{Q}{C_{d} b \sqrt{2 g}} ; K_{L}$ es un coeficiente con valores de 0 a 1 que aplicado a la derivada $K p_{1}$ ayuda a 
2022, Instituto Mexicano de Tecnología del Agua

Tecnología y

Ciencias $₫$ Agua
Open Access bajo la licencia CC BY-NC-SA 4.0 (https://creativecommons.org/licenses/by-nc$\mathrm{sa} / 4.0 /$ )

suavizar las perturbaciones generadas por el movimiento de la compuerta; los coeficientes $K_{p 1}$ y $K_{p 2}$ se definen como:

$K_{p_{1}}=-\frac{1}{2} F_{1} \cdot\left(y_{r}-y_{3}\right)^{-1.5}$

$K_{p_{2}}=\frac{3}{8} F_{1} \cdot\left(y_{r}-y_{3}\right)^{-2.5}$

Para este algoritmo se requiere definir el intervalo de tiempo que permanece activo el control ( $T_{\text {control }}$ ) y el intervalo de tiempo en que se calculará la nueva maniobra $\left(T_{\text {maniobra }}\right)$. Este control tiene la ventaja de que permite estimar el valor de los coeficientes $K p_{s}$ en función de las mismas propiedades físicas de la descarga. Como se puede notar en su formulación, se enfoca en el control de nivel.

\section{Control Stringam}

Stringam y Wahl (2015) proponen una fórmula pensada en personas que no están familiarizadas con técnicas de control. Se trata de un algoritmo de control de tipo proporcional, ya que se establece una proporción entre la actual apertura de compuerta ( $p g p)$ y gasto $(p Q)$, con la nueva apertura de compuerta (ngp) para hacer circular el gasto deseado $(n Q)$. Dada la 
2022, Instituto Mexicano de Tecnología del Agua

Tecnología y

Ciencias $\stackrel{\Xi}{\Im}$ Agua
Open Access bajo la licencia CC BY-NC-SA 4.0 (https://creativecommons.org/licenses/by-ncsa/4.0/)

proporción, es posible obtener la nueva apertura de compuerta para cualquier gasto aplicando una regla de tres:

$$
\frac{n g p}{n Q}=\frac{p g p}{p Q}
$$

Si la nueva apertura de compuerta ( $n g p$ ) se expresa en términos del cambio de la posición $(\Delta g p)$ y de la posición actual de la compuerta $(p g p)$, al sustituir $n g p$ en la proporción anterior y despejar $\Delta g p$, resulta que el cambio de apertura de la compuerta depende proporcionalmente $\left(K_{p}=\right.$ $\left.\frac{p g p}{p Q}\right)$ del cambio en el gasto $(e=n Q-p Q)$ :

$\Delta g p=\frac{p g p}{p Q}(n Q-p Q)=e\left(\frac{p g p}{p Q}\right)$

Así, se observa que esta ecuación contiene el coeficiente de ganancia proporcional. Stringam y Wahl (2015) mencionan que este método es apropiado cuando el fenómeno es de frecuencia corta, por lo que para el caso de los canales puede entrar en resonancia si se llegaran a hacer movimientos de compuerta muy rápidos. Los tiempos de control dependen del cambio de volumen $(\Delta V)$ requerido en el canal para lograr hacer el cambio de gasto propuesto.

$\Delta V=L B(\Delta y)$ 
2022, Instituto Mexicano de Tecnología del Agua

Tecnología y

Ciencias $\stackrel{\Xi}{\triangleleft}$ gua
Open Access bajo la licencia CC BY-NC-SA 4.0 (https://creativecommons.org/licenses/by-nc$\mathrm{sa} / 4.0 /$ )

donde $L$ es la longitud del tramo; $B$ es el promedio del ancho de la superficie libre ante los rangos de flujo en análisis, y $\Delta y$ es el cambio en el tirante necesario para obtener el nuevo gasto. Entonces el tiempo requerido para hacer el cambio de gasto es:

$\Delta t=\frac{\Delta V}{\Delta Q}=L B \frac{\Delta H}{\Delta Q}=L B \frac{d H}{d Q}$

La derivada $\frac{d H}{d Q}$ dependerá de la estructura de control de gasto. Este control está enfocado en el gasto y se puede aplicar ante una operación manual.

\section{Control proporcional integral y derivativo (PID)}

El control PID es de tipo feedback, se alimenta de los errores del pasado y es definido en función del error de la variable de control $e(t)$. Los errores son afectados por los coeficientes de ganancia proporcional $\left(K_{p}\right)$, integral $\left(K_{i}\right)$ y derivativa $\left(K_{d}\right)$ del controlador (Astrom \& Murray, 2008). La señal de salida $y(t)$ estará dada por el modelo (10):

$y(t)=K_{p} e(t)+k_{i} \int_{0}^{t} e(t) d t+k_{d} \frac{d e}{d t}$ 
2022, Instituto Mexicano de Tecnología del Agua

Tecnología y

Ciencias $\stackrel{\Xi}{\Im}$ Agua
Open Access bajo la licencia CC BY-NC-SA 4.0 (https://creativecommons.org/licenses/by-nc$\mathrm{sa} / 4.0 /)$

En la calibración de los coeficientes $K_{p}, K_{i}$ y $K_{d}$ se aplican las herramientas de diseño y análisis de sistemas de control de MATLAB® (The Mathworks, I. N., 2019). Cuando no se conoce el modelo de planta, una opción para identificar el sistema físico, es decir, calcular los coeficientes $K_{p}, K_{i}$ y $K_{d}$, es partir de datos medidos en la entrada y salida del sistema. Para el caso de aplicación mostrado en este artículo, se utilizan las respuestas del canal al aplicar control por retardos. Se toma como entrada el error en el tirante y como salida las aperturas de compuerta.

\section{Control con redes neuronales artificiales (RNA)}

El método numérico de redes neuronales artificiales trata de imitar el comportamiento del cerebro humano. Pasa por un proceso de entrenamiento, en el cual, mediante una variable de entrada, se busca llegara reconocer una variable de salida conocida. Una vez que el sistema ha aprendido puede identificary clasificar patrones nunca vistos (Nunesda-Silva, Hernane-Spatti, Andrade-Flauzino, \& Bartocci-Liboni, 2017). Este método ha mostrado buenos resultados ante problemas no lineales (Durdu, 2004; Ruslan, 2014; Mohapatra \& Lenka, 2016). En la identificación de la dinámica del canal con RNA se utilizan como señal de 
2022, Instituto Mexicano de Tecnología del Agua

Tecnología y

Ciencias $\stackrel{\Xi}{\unlhd}$ gua
Open Access bajo la licencia CC BY-NC-SA 4.0 (https://creativecommons.org/licenses/by-nc$\mathrm{sa} / 4.0 /)$

entrada las variaciones del tirante $\left(\Delta y_{J}^{n}\right)$ con respecto al tirante objetivo $\left(y_{f}\right)$, y variaciones de gasto al inicio del tramo $\left(\Delta Q_{1}^{n}\right)$ y variaciones en apertura de la compuerta $\left(\Delta w^{n}\right)$ como variable de salida:

$\Delta y_{J}^{n}=y_{J}^{n}-y_{f}$

En este estudio se utiliza una red con arquitectura NARXNET (por las siglas de Nonlinear Autoregresive Network with exogenus inputs), ya que mostró buenos resultados en la identificación del tramo "El Bocal" de acuerdo con Hernández, Feliu y Rivas (2017). Este tipo de red es dinámica y autorregresiva con conexiones de retroalimentación a varias capas de la red. El modelo NARX es descrito por la Ecuación (12) (Haykin, 2010). (Figura 3).

$w^{n+1}=F\left(w^{n}, \ldots, w^{n-q+1} ; x^{n}, \ldots, x^{n-q+1}\right)$

donde $w^{n+1}$ es el siguiente valor de la señal dependiente de salida, en este caso la apertura de compuerta; $F$ es una función no lineal; $x^{n}$ representa las entradas originadas desde afuera de la red, que estará integrada por $\Delta y_{J}^{n}$ y $\Delta Q_{1}^{n}$. 
2022, Instituto Mexicano de Tecnología del Agua Open Access bajo la licencia CC BY-NC-SA 4.0 (https://creativecommons.org/licenses/by-nc$\mathrm{sa} / 4.0 /$ )

\section{Capa de entrada}

Capas ocultas
Capa de salida

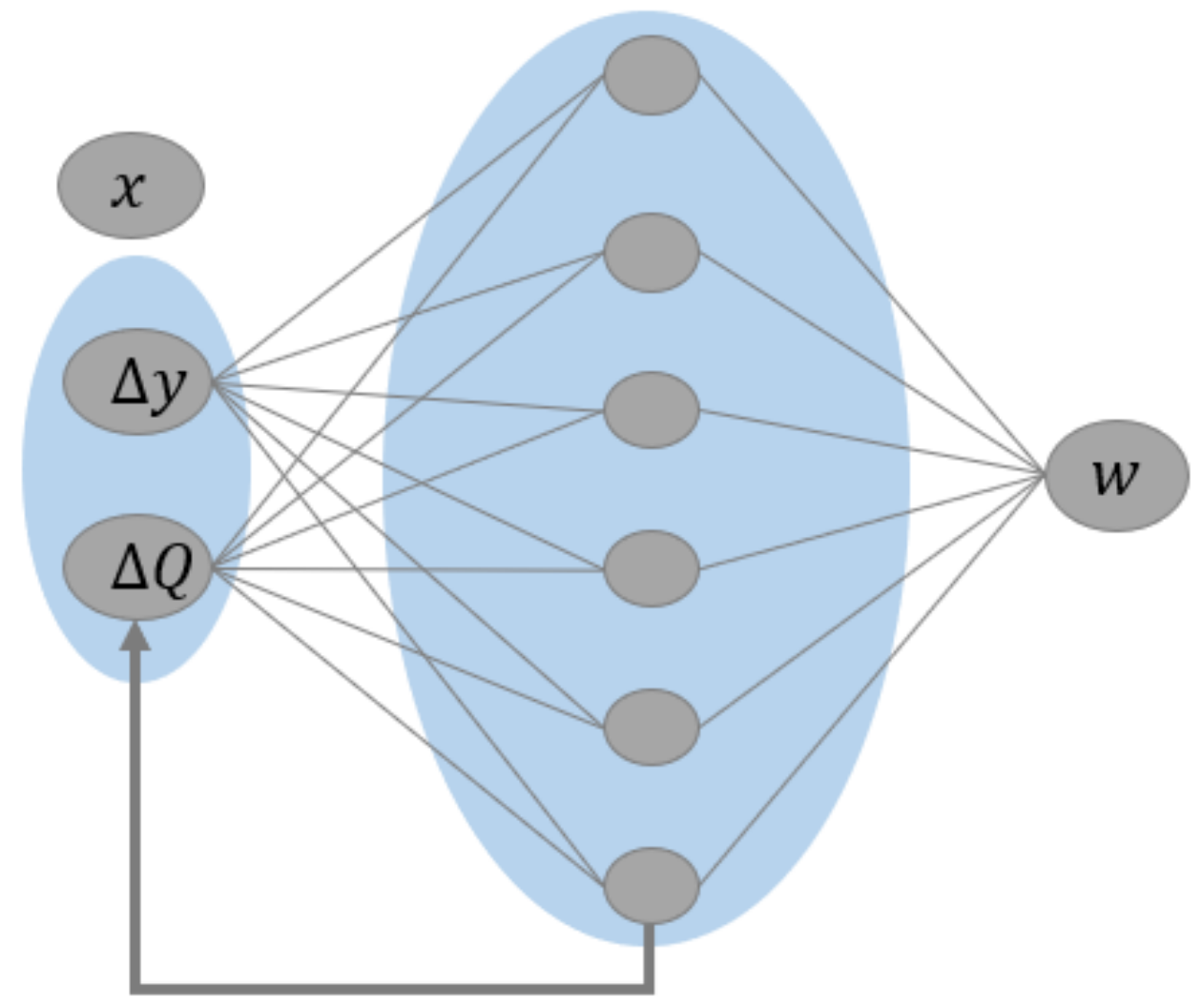

Figura 3. Arquitectura de la RNA tipo NARX utilizada. En la entrada $x(t)$ hay dos clases de datos $\Delta y_{J}^{n}$ y $\Delta Q_{1}^{n}$.

La serie de datos de entrenamiento se generó con una simulación en SFT de 24 horas, en la que se asignó como hidrograma a la cabeza del canal una secuencia de pulsos entre 63 y $77 \mathrm{~m}^{3} / \mathrm{s}$ con intervalos de dos horas. Como estrategia de control se aplicó un control local PI, con $k p=$ 0.3533 y $k_{i}=-0.0087$. Los parámetros usados fueron $t_{\text {control }}=900 \mathrm{~s}$; 
2022, Instituto Mexicano de Tecnología del Agua

Tecnología y

Ciencias $\stackrel{\unlhd}{\unlhd}$ Agua
Open Access bajo la licencia CC BY-NC-SA 4.0 (https://creativecommons.org/licenses/by-nc$\mathrm{sa} / 4.0 /)$

$t_{\text {maniobra }}=1200 \mathrm{~s}$, y $\Delta t=30 \mathrm{~s}$. En la capa oculta se utilizó una función de activación tangente sigmoidal y pureline en la capa de salida, mientras que en el entrenamiento se aplicó el método Levenberg-Marquardt.

\section{Control mixto}

El control mixto consiste en una combinación entre control global y uno local, por lo general automático. Este tipo de control es una alternativa a los sistemas de control totalmente manuales o automáticos. VanOverloop et al. (2014) mencionan que esta estrategia permite mantener al ser humano involucrado por completo en el ciclo de control y a la vez ofrece mejores resultados que el control por retardos. Además de proporcionar seguridad a los equipos, promueve la aceptación de nuevas tecnologías y tiene menor movimiento de compuertas que un control totalmente automático.

En esta estrategia de control, las aperturas de compuerta importantes se programan para tener control de gastos. Posteriormente se activa un control automático local para hacer pequeñas correcciones durante una ventana de tiempo, llamada tiempo de control, y así corregir el nivel de operación. En la Tabla 1 se muestran las combinaciones propuestas para este estudio. 
2022, Instituto Mexicano de Tecnología del Agua

Tecnología y

Ciencias $\stackrel{\Xi}{\Im}$ Aua
Open Access bajo la licencia CC BY-NC-SA 4.0 (https://creativecommons.org/licenses/by-ncsa/4.0/)

Tabla 1. Estrategias de control mixto.

\begin{tabular}{|l|l|l|}
\hline Nombre & \multicolumn{1}{|c|}{$\begin{array}{c}\text { Controles } \\
\text { involucrados }\end{array}$} & \multicolumn{1}{|c|}{ Descripción } \\
\hline Mixto 01 & $\begin{array}{l}\text { Retardo } \\
\text { perturbatorios }\end{array}$ & $\begin{array}{l}\text { Consiste en programar los cambios } \\
\text { fuertes de la compuerta con base en el } \\
\text { método de retardo y los ajustes } \\
\text { menores con un control local } \\
\text { perturbatorio }\end{array}$ \\
\hline Mixto 02 & Retardo + PID & $\begin{array}{l}\text { En este control mixto, los ajustes } \\
\text { menores se calculan con un control } \\
\text { proporcional integral (PI) }\end{array}$ \\
\hline Mixto 03 & $\begin{array}{l}\text { Balance de masa }+ \\
\text { perturbatorios }\end{array}$ & $\begin{array}{l}\text { Se aplica compensación de volumen y } \\
\text { posteriormente corrección al tirante en } \\
\text { el nivel de operación mediante un } \\
\text { control local de tipo perturbatorio }\end{array}$ \\
\hline
\end{tabular}

\section{Indicadores de desempeño del control en canales de riego}

La ASCE propuso indicadores de desempeño para comparar el funcionamiento de diferentes algoritmos de control (Clemmens, Kacerek, 
2022, Instituto Mexicano de Tecnología del Agua

Tecnología y

Ciencias $\stackrel{\Xi}{\Im}$ Agua
Open Access bajo la licencia CC BY-NC-SA 4.0 (https://creativecommons.org/licenses/by-nc$\mathrm{sa} / 4.0 /)$

Grawitz, \& Schuurmans, 1998). En este estudio se utilizan el máximo error absoluto (MAE), la integral absoluta del error (IAE) y la integral absoluta de los movimientos de la compuerta (IAW), descritos en las ecuaciones (13) a (15). Estos indicadores permiten vigilarel máximo error generado por el algoritmo de control, la velocidad de respuesta y la tendencia del error final a cero:

$M A E=\max \left(\left|y_{f}-y_{o}\right|\right) / y_{o}$

$I A E=\frac{\frac{\Delta t}{T_{(12-24 h)}} \sum_{t=0}^{T}\left|y_{f}-y_{o}\right|}{y_{o}}$

$I A W=\sum_{t=t_{1}}^{t_{2}}\left(\left|W_{t}-W_{t-1}\right|\right)-\left|W_{t_{1}}-W_{t_{2}}\right|$

Donde $y_{f}$ es el tirante de operación en metros, $y_{o}$ es el tirante medido en el punto de control.

Para calcular el indicador económico e hidráulico se aplica el siguiente proceso:

1. Simular la política de operación del canal de riego en el sistema SFT con los diferentes modelos de control de apertura de las compuertas para un escenario de modificación de gasto deseado $\left(Q_{n}\right)$.

2. Calcular las diferencias de volúmenes entre el gasto deseado $\left(Q_{n}\right)$ y el realmente entregado $\left(Q_{n r}\right)$. Se distingue si el error se debe a gasto entregado en exceso $\left(\Delta V_{e}\right)$ o faltante $\left(\Delta V_{f}\right)$ con la siguiente expresión: 
2022, Instituto Mexicano de Tecnología del Agua

Tecnología y

Ciencias $₫$ Agua
Open Access bajo la licencia CC BY-NC-SA 4.0 (https://creativecommons.org/licenses/by-nc$\mathrm{sa} / 4.0 /)$

$$
\Delta V_{e / f}=\int_{t_{1}}^{t_{2}}\left(Q_{n}-Q_{n_{r}}\right) d t=\sum_{n=1}^{N}\left(Q_{n}-Q_{n_{r}}\right) d t
$$

Se analizan tres formas de evaluar económicamente los errores en la entrega de volúmenes de agua. El primero es con base en el precio por metro cúbico de agua que se debe pagar para cubrir los costos de operación del distrito de riego. El segundo se refiere al precio sombra del agua en el cultivo de mayor producción en la zona de riego. El tercero tiene que ver con la productividad económica de un cultivo y su consumo de agua en una determinada zona de riego. El procedimiento para evaluar económicamente el volumen del agua consiste en analizar la operación y calcular el valor de la producción del metro cúbico de agua en la zona de riego, como se describe a continuación:

1. Calcular el rendimiento de los cultivos de la zona.

2. Calcular la lámina neta de agua requerida para cada cultivo en particular y posteriormente evaluar el volumen requerido para regar toda la superficie correspondiente a cada cultivo.

3. Hacer un pronóstico del precio de venta del producto de acuerdo con datos históricos. Para esto se hará uso de la base de datos del Sistema Nacional de Información e Integración de Mercado (SNIIM) de la Secretaría de Economía (2019).

4. Calcular la relación entre el precio de la producción y el volumen de agua utilizado. 
2022, Instituto Mexicano de Tecnología del Agua Open Access bajo la licencia CC BY-NC-SA 4.0 (https://creativecommons.org/licenses/by-nc$\mathrm{sa} / 4.0 /$ )

\section{Caso de estudio}

El canal principal del Carrizo, localizado en el Distrito de Riego 076 (Valle del Carrizo, Sinaloa), fue diseñado para conducir el agua desde la presa Josefa Ortiz de Domínguez, a fin de irrigar 43000 ha del distrito del Carrizo; 35000 ha de la ampliación Fuerte-Mayo; 6000 ha de los módulos la Capilla y Los Llanos; esto es, un total de 84000 ha. Para este estudio se seleccionaron los primeros $32 \mathrm{~km}$ del canal principal del Carrizo, conocido como tramo muerto, pues no tiene extracciones hasta el km $32+000$ (Figura 4). 
Tecnología y
2022, Instituto Mexicano de Tecnología del Agua Open Access bajo la licencia CC BY-NC-SA 4.0 (https://creativecommons.org/licenses/by-ncsa/4.0/)

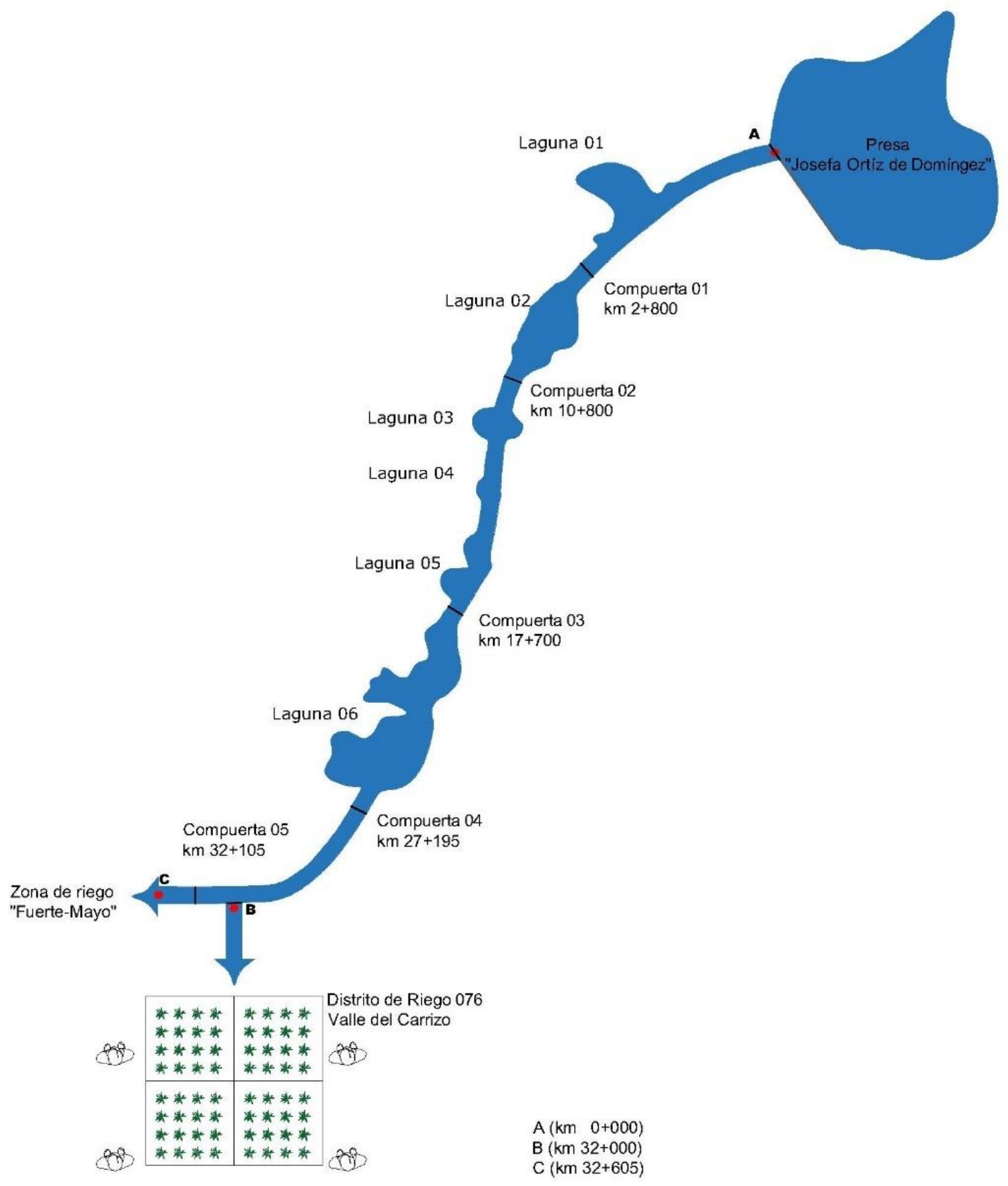

Figura 4. Esquema del canal principal en estudio. El punto A es el inicio del canal; en el punto B se ubica la toma lateral hacia el DR 076 Valle 
2022, Instituto Mexicano de Tecnología del Agua

Tecnología y

Ciencias $\stackrel{\Xi}{\unlhd}$ gua
Open Access bajo la licencia CC BY-NC-SA 4.0 (https://creativecommons.org/licenses/by-nc$\mathrm{sa} / 4.0 /)$

del Carrizo, y el punto $C$ es el fin del tramo del canal en estudio, el flujo continuo hacia el Fuerte-Mayo.

Este es un caso interesante de evaluar, ya que atraviesa lagunas de regulación que se extienden desde $1.7 \mathrm{~km}$ hasta $0.6 \mathrm{~km}$ la menor, medidos sobre el eje del canal. En total hay $8.740 \mathrm{~km}$ de lagunas no revestidas y con vegetación, que inducen un retardo adicional o también pueden ser utilizadas para adelantar volúmenes en la operación, pero en ambos casos tienen influencia en la dinámica del canal. El tramo muerto conduce el agua para abastecer al DR 076 Valle del Carrizo en la primera toma y el canal continúa hacia la zona de riego Fuerte-Mayo. El agua se destina a uso agrícola y doméstico, y es un posible punto de conflicto por las disputas en la entrega de los volúmenes, al ser una zona árida.

Geometría del tramo. El canal principal es de sección trapezoidal de $5 \mathrm{~m}$ de plantilla, taludes de $1.5: 1$ y pendiente de $S_{o}=0.0003 \mathrm{del} \mathrm{km} 0+000$ al km 20+800, y de este kilometraje al km 26+100 la pendiente es de 0.0005. El resto de los parámetros se conserva en la sección transversal del canal.

Geometría de las estructuras. En este tramo del canal hay represas con dos compuertas de $4.15 \mathrm{~m}$ de ancho, por lo que el coeficiente de descarga se calculará con el modelo de Swamee (1992). En este estudio se considera que los diques no reciben aportaciones por lluvia en la temporada de operación del canal.

Datos hidráulicos del canal. El tramo de $0+000$ a $32+000$ es operado con gastos de $70 \mathrm{~m}^{3} / \mathrm{s}$ y tirante normal de $4.26 \mathrm{~m}$. El canal tiene tramos revestidos de concreto con rugosidad $n=0.015$, y en los tramos 
2022, Instituto Mexicano de Tecnología del Agua

Tecnología y

Ciencias $₫$ Agua
Open Access bajo la licencia CC BY-NC-SA 4.0 (https://creativecommons.org/licenses/by-nc$\mathrm{sa} / 4.0 /)$

sin revestimiento, sinuosos, flujo de baja velocidad y un poco de hierba, $n=0.030$ (Chaudhry, 2008).

Operación del canal. La fuente de abastecimiento del canal es la presa Josefa Ortiz de Domínguez, el punto en el sitio A de la Figura 4. Desde este sitio hasta el km 32+080 hay una derivación hacia el DR 076 Valle del Carrizo (B) y el canal continúa hacia la zona de riego MayoFuerte (C). El agua que conduce este canal es para uso agrícola, pero tiene una demanda continua anual para uso público urbano de $0.5 \mathrm{~m}^{3} / \mathrm{s}$. Los ciclos agrícolas son de otoño-invierno y se suspende la demanda a los cultivos en el periodo primavera-verano. Para los análisis se propone simular en el programa SFT la operación de ocho horas, tal como se indica en la Tabla 2, y se evalúa un incremento en la demanda en el punto B (DR 076 Valle del Carrizo), pero se conservaría para el gasto de entrega en el punto $C$ (distrito Fuerte-Mayo) (Figura 5).

Tabla 2. Programa de operación de ocho horas. Hay un incremento en la demanda de la toma en B y en C continua constante.

\begin{tabular}{|c|c|c|c|}
\hline \multirow{2}{*}{ Horario } & \multicolumn{3}{|c|}{ Puntos de entrega } \\
\cline { 2 - 4 } & A & B & C \\
\hline $0: 00$ & 70 & 15 & 55 \\
\hline $0: 05$ & 70 & 15 & 55 \\
\hline $0: 10$ & 77 & 15 & 55 \\
\hline $1: 10$ & 77 & 15 & 55 \\
\hline $1: 15$ & 77 & 22 & 55 \\
\hline
\end{tabular}


2022, Instituto Mexicano de Tecnología del Agua

Tecnología y

Ciencias $\stackrel{\Xi}{\Im}$ Agua
Open Access bajo la licencia CC BY-NC-SA 4.0 (https://creativecommons.org/licenses/by-nc$\mathrm{sa} / 4.0 /$ )

\begin{tabular}{|l|l|l|l|}
\hline $8: 00$ & 77 & 22 & 55 \\
\hline
\end{tabular}

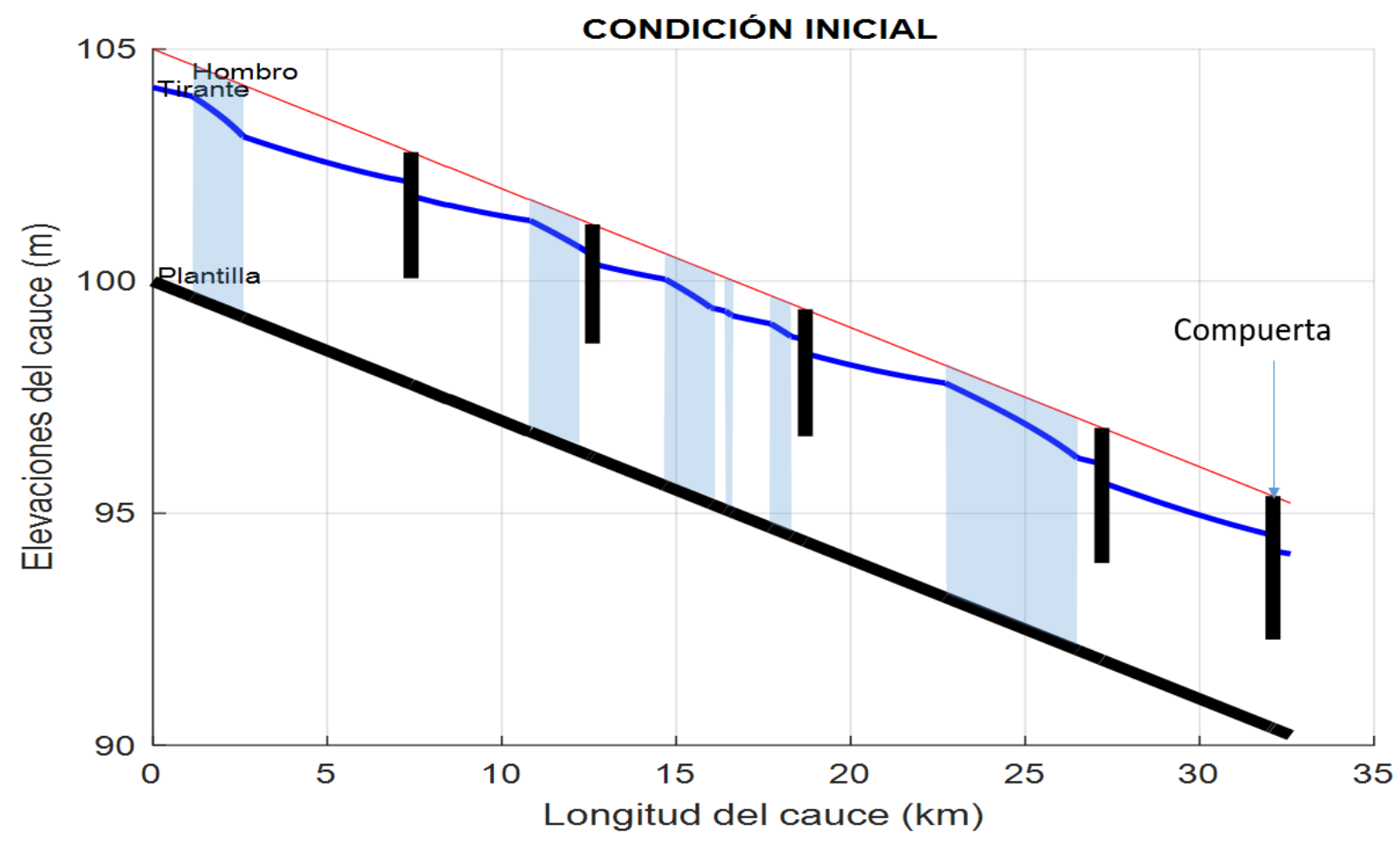

Figura 5. Perfil de flujo del canal. Las franjas sombreadas muestran la localización de lagunas sobre el eje del canal ( $n=0.30)$, compuertas y perfil de flujo para $Q=70 \mathrm{~m}^{3} / \mathrm{s}$, y extracción $q_{\text {lat }}=15 \mathrm{~m}^{3} / \mathrm{s}$.

En la operación de las compuertas, los cambios en la apertura deberán ser menores o iguales al 5 \% de la apertura actual (Stringam \& Wahl, 2015), con la finalidad de evitar aperturas o cierres abruptos que induzcan inestabilidad en el sistema. 


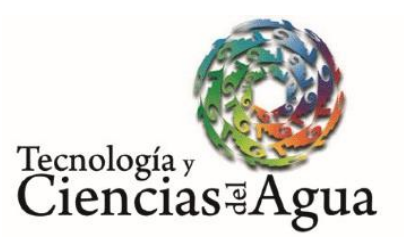

2022, Instituto Mexicano de Tecnología del Agua

Open Access bajo la licencia CC BY-NC-SA 4.0 (https://creativecommons.org/licenses/by-nc$\mathrm{sa} / 4.0 /)$

\section{Valor económico del agua en la zona de riego}

Como se mencionó anteriormente, se consideran tres formas de evaluar los fallos en la operación. Para evaluar el precio del agua de riego con respecto al maíz se utilizó el estudio presentado por Bierkens, Reinhard, De-Brujin, Veninga yWada (2019), donde analizan el precio sombra del agua de riego en los países con mayor agotamiento de aguas subterráneas, entre los que aparece México. En la función de producción utilizada por Bierkens et al. (2019) se considera el uso de agua verde (precipitación), azul (riego), no renovable (subterránea), y se involucran los costos de semillas, fertilizantes, herbicidas, energía, labor y capital.

En la Tabla 3 se muestran los precios sombra calculados para cinco cultivos de México, con base en FAOSTAT, del periodo 1991-2010 (Bierkens et al., 2019). Torres-Sombra y García (2015) mencionan que, para que se cubran los costos de operación de los organismos que administran el recurso en los distritos de riego de Sinaloa, México, el agua debería costar US\$0.014/MX\$0.221 $\mathrm{m}^{3}$ (US $\$ 1=\mathrm{MX} \$ 15.82$ ).

Tabla 3. Precio sombra del agua de riego en cinco cultivos de México. Fuente: Bierkens et al. (2019). 
2022, Instituto Mexicano de Tecnología del Agua

Tecnología y Open Access bajo la licencia CC BY-NC-SA 4.0 (https://creativecommons.org/licenses/by-ncsa/4.0/)

\begin{tabular}{|l|c|c|c|c|c|}
\hline Periodo & Trigo & Papa & Maíz & Arroz & Cítricos \\
& (US\$) & (US\$) & (US\$) & (US\$) & (US\$) \\
\hline $2006-2010$ & 0.022 & 0.156 & 0.053 & 0.004 & 0.081 \\
\hline
\end{tabular}

Por otro lado, se hace una proyección de la productividad del metro cúbico de agua en las zonas de riego, en la cual se considera la superficie y el rendimiento de los 11 principales cultivos (Conagua, 2018). Se evaluó la lámina neta requerida por cada cultivo y posteriormente el volumen requerido ante una eficiencia del $76 \%$. A partir de los registros de precios del Sistema Nacional de Información e Integración de Mercados (SNIIM) de la Secretaría de Economía (2019), se hizo una proyección para los siguientes meses. Con las superficies cultivadas y el rendimiento reportado por la Conagua (2018), en la Tabla 4 se muestra el cálculo del volumen de agua requerida por un cultivo y los precios de venta. Los resultados son que la productividad media del agua es de US\$0.70 $/ \mathrm{m}^{3} \mathrm{y}$ la del maíz, cultivo de mayor extensión después del trigo, es de US\$0.26/ $\mathrm{m}^{3}$.

Tabla 4. Lámina de riego y volumen neto requerido por los cultivos de la zona de riego. Fuente: elaboración propia con datos de ${ }^{*}$ Conagua (2018) y ${ }^{* *}$ Secretaría de Economía (2019)

\begin{tabular}{|l|c|c|c|c|c|c|c|}
\hline & Núm. & Cultivo & A $^{*}$ & Ya & Ln_total & $\begin{array}{c}2019 \\
\text { PMR }^{* *}\end{array}$ & $\begin{array}{c}\text { Productividad } \\
\text { del agua }\end{array}$ \\
\hline & & & $($ ha) & $($ ton/ha) & $\mathbf{( m )}$ & $\mathbf{( U S \$ )}$ & $\mathbf{\$} / \mathbf{m}^{\mathbf{3}}$ \\
\hline
\end{tabular}


2022, Instituto Mexicano de Tecnología del Agua

Tecnología y

Ciencias $₫$ Agua
Open Access bajo la licencia CC BY-NC-SA 4.0 (https://creativecommons.org/licenses/by-nc$\mathrm{sa} / 4.0 /$ )

\begin{tabular}{|c|c|c|c|c|c|c|c|}
\hline \multirow{11}{*}{ 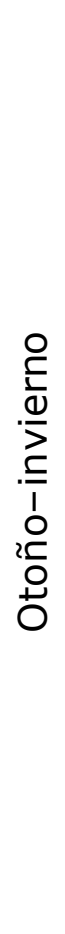 } & 1 & Trigo grano & 62745 & 5.6 & 0.552 & 176.14 & 0.14 \\
\hline & 2 & Maíz grano & 6357 & 9.6 & 0.811 & 291.58 & 0.26 \\
\hline & 3 & Tomate & 1919 & 18.5 & 0.737 & 311.85 & 0.60 \\
\hline & 4 & Frijol & 906 & 1.6 & 0.442 & 753.63 & 0.21 \\
\hline & 5 & Sorgo grano & 832 & 5.7 & 0.941 & 151.71 & 0.07 \\
\hline & 6 & Espárrago & 507 & 5.9 & 1.106 & 4417.88 & 1.80 \\
\hline & 7 & Calabaza & 491 & 15.0 & 0.460 & 467.77 & 1.16 \\
\hline & 8 & Cártamo & 20 & 1.6 & 0.491 & 436.59 & 0.11 \\
\hline & 9 & Garbanzo & 259 & 1.6 & 0.430 & 1031.18 & 0.29 \\
\hline & 10 & Papa & 130 & 24.5 & 0.552 & 779.63 & 0.003 \\
\hline & 11 & Sandía & 115 & 45.0 & 0.460 & 415.80 & 3.10 \\
\hline
\end{tabular}

\section{Resultados}

\section{Control global}

El calendario de aperturas de compuertas resultó en el programa de la Tabla 5. El operador deberá moverse a unos $25 \mathrm{~km} / \mathrm{h}$ de un punto de 
2022, Instituto Mexicano de Tecnología del Agua

Tecnología y

Ciencias $₫$ Agua
Open Access bajo la licencia CC BY-NC-SA 4.0 (https://creativecommons.org/licenses/by-nc$\mathrm{sa} / 4.0 /)$

control al siguiente, lo que queda condicionado por el estado de los caminos de terracería. En una segunda prueba se verificó que no hay cambios significativos en los resultados al redondear las horas de accionamiento de compuerta a múltiplos de cinco minutos.

Tabla 5. Programa de operación por retardos de compuerta.

\begin{tabular}{|c|r|r|r|r|r|}
\hline Compuerta & \multirow{2}{*}{ Localización } & \multicolumn{2}{|c|}{ Operación 1 } & \multicolumn{2}{c|}{ Operación 2 } \\
\cline { 3 - 6 } & & HH:MM:SS & apertura & HH:MM:SS & Apertura \\
\hline 3 & $\mathrm{Km} \mathrm{2+600}$ & $0: 28: 59$ & 2.38 & - & - \\
\hline 6 & $\mathrm{Km} \mathrm{10+800}$ & $0: 42: 21$ & 2.64 & - & - \\
\hline 13 & $\mathrm{Km} \mathrm{17+700}$ & $0: 57: 35$ & 2.44 & - & - \\
\hline 18 & $\mathrm{Km} \mathrm{27+195}$ & $1: 19: 02$ & 2.11 & $2: 34: 02$ & 2.11 \\
\hline 23 & $\mathrm{Km} \mathrm{32+085}$ & $1: 32: 05$ & 1.85 & $2: 47: 05$ & 1.72 \\
\hline
\end{tabular}

\section{Control local}

Con el control derivado de métodos perturbatorios se actualizan en cada intervalo de tiempo de control los coeficientes $k^{\prime} s$. Los coeficientes de ganancia del control PID obtenidos tras la identificación del canal en el módulo de "Análisis y diseño de sistemas de control" en MATLABß (The Mathworks, I. N., 2019) se muestran en la Tabla 6. 
2022, Instituto Mexicano de Tecnología del Agua

Tecnología y

Ciencias $₫$ Agua
Open Access bajo la licencia CC BY-NC-SA 4.0 (https://creativecommons.org/licenses/by-nc$\mathrm{sa} / 4.0 /$ )

Tabla 6. Coeficientes del controlador PID.

\begin{tabular}{|c|c|c|}
\hline Compuerta & $\boldsymbol{k p}$ & $\boldsymbol{k i}$ \\
\hline 1 & -0.3533 & -0.0087 \\
\hline 2 & -0.4060 & -0.0061 \\
\hline 3 & -0.4060 & -0.0061 \\
\hline 4 & -0.3533 & -0.0081 \\
\hline 5 & -0.4060 & -0.0061 \\
\hline
\end{tabular}

El control de Stringam y Wahl (2015) calcula con la Ecuación (7) la corrección $\Delta w$ cada cinco minutos y ejecuta el cambio en la apertura de la compuerta en dos minutos. Así, se consiguió estabilizar el nivel de operación aguas arriba de la compuerta C en aproximadamente 20 minutos.

En la condición inicial, la compuerta de la toma lateral (toma B) tiene una apertura $w_{o}=0.28 \mathrm{~m}$; a la $1: 20 \mathrm{~h}$ se comienza a abrir hasta alcanzar la apertura $w_{1}=0.42 \mathrm{~m}$. Con este cambio en la compuerta lateral la extracción cambia de 15 a $22 \mathrm{~m}^{3} / \mathrm{s}$. En la Figura 6 se muestran las variaciones de la apertura de la compuerta C sobre el canal principal. La operación de la compuerta lateral se supone manual, su apertura dura cinco minutos y posteriormente queda fija en $w_{1}$. Debido a esto, y como puede observarse en la Figura 7, la descarga lateral depende sólo del tirante aguas arriba de la toma $B$, mismo que dependerá del control en la compuerta C. 
2022, Instituto Mexicano de Tecnología del Agua

Open Access bajo la licencia CC BY-NC-SA 4.0 (https://creativecommons.org/licenses/by-nc$\mathrm{sa} / 4.0 /)$
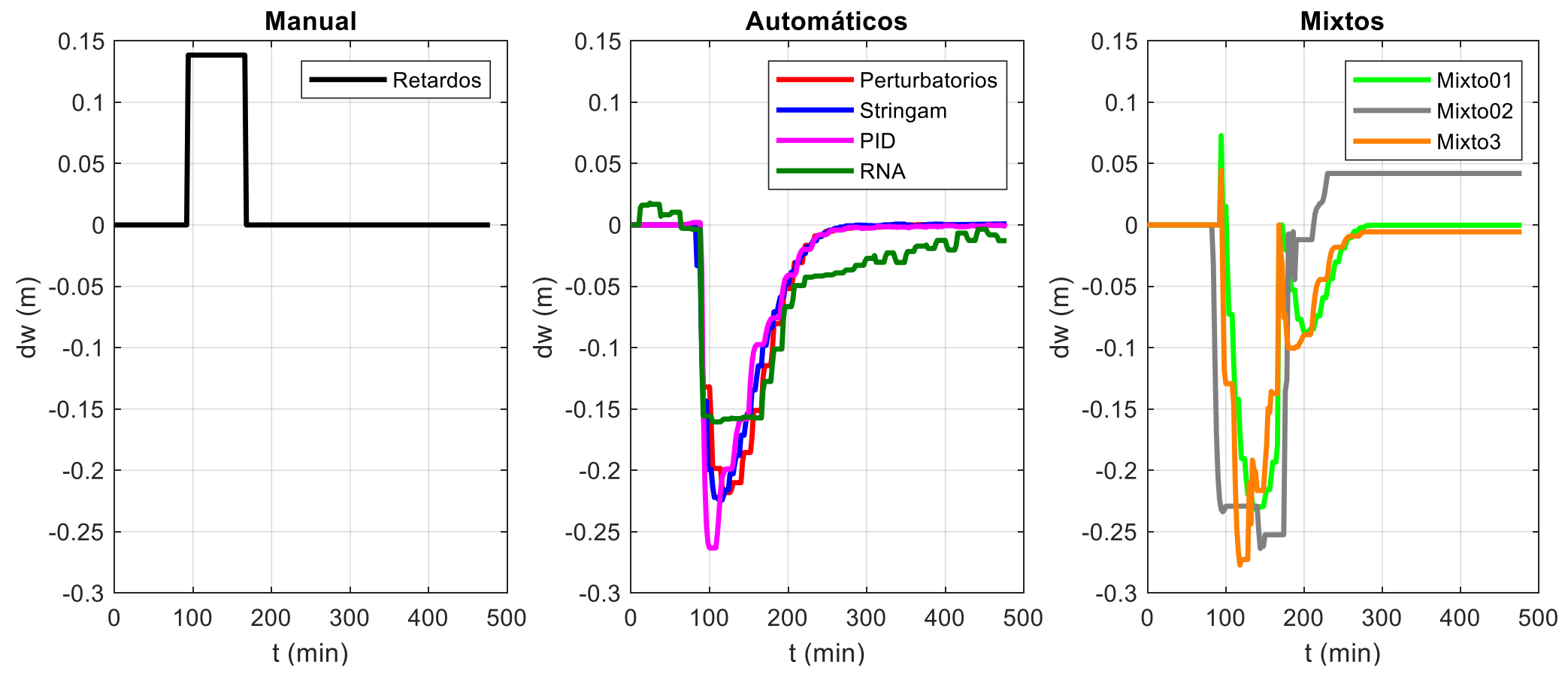

Figura 6. Ajustes en apertura de compuerta $C$ (canal principal). En este gráfico se observan los movimientos de compuerta ejecutados por cada categoría de algoritmo de control. Aquí se aprecia la respuesta de los algoritmos de control al incremento en la extracción lateral (que inicia a la $1: 10 \mathrm{~h}$ ), ya que la compuerta $\mathrm{C}$ comienza a tener respuesta a la $1: 32$ $\mathrm{h}$ (retardos), 1:10 h (PID), 1:14 (Stringam), 1:16 (perturbatorios), 1:32 $\mathrm{h}$ (mixto 1 y 3 ) y $1: 20 \mathrm{~h}$ (mixto 2 ). 
2022, Instituto Mexicano de Tecnología del Agua

Tecnología y

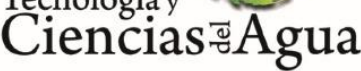

Open Access bajo la licencia CC BY-NC-SA 4.0 (https://creativecommons.org/licenses/by-nc$\mathrm{sa} / 4.0 /)$
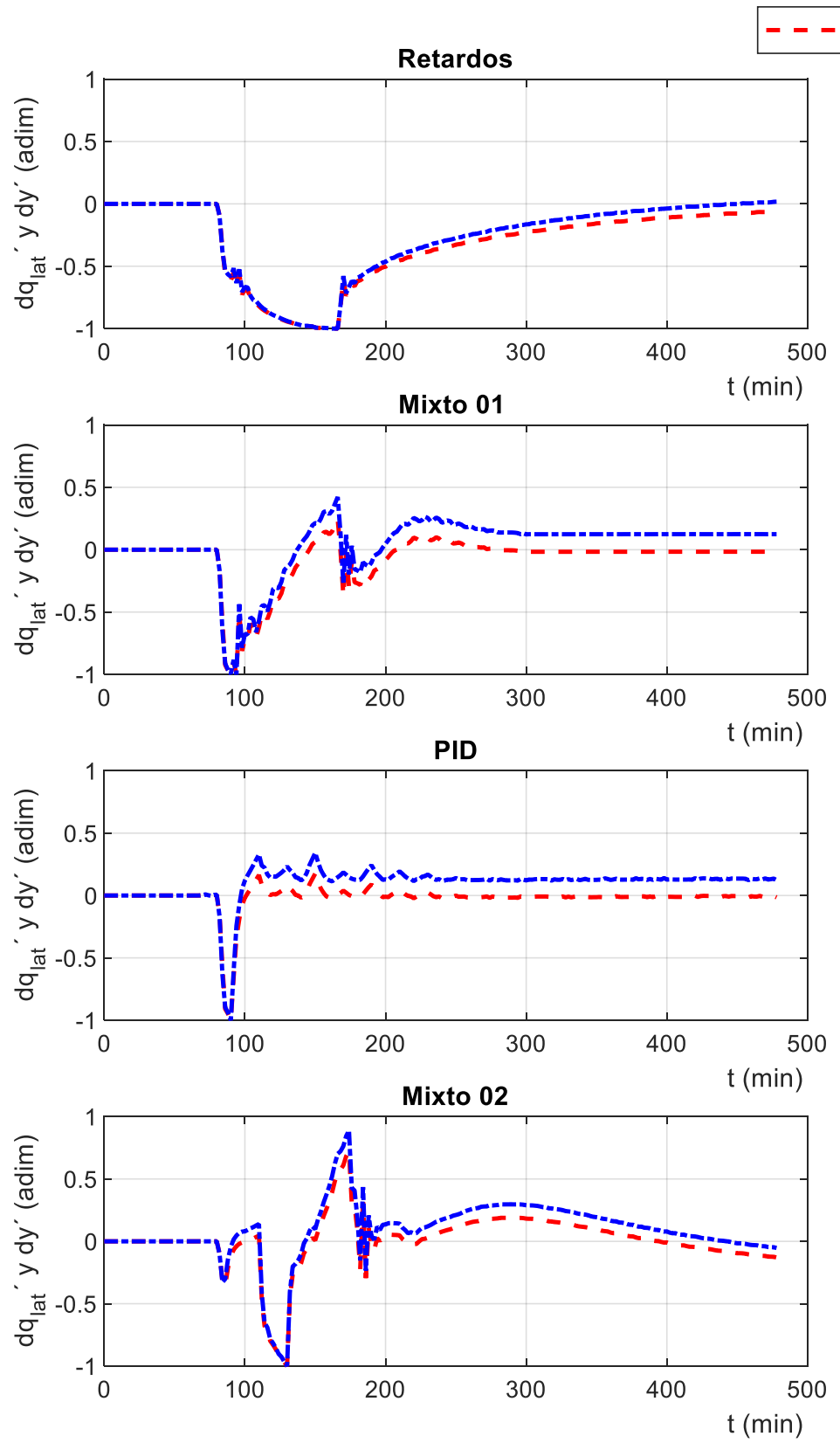

Perturbatorios
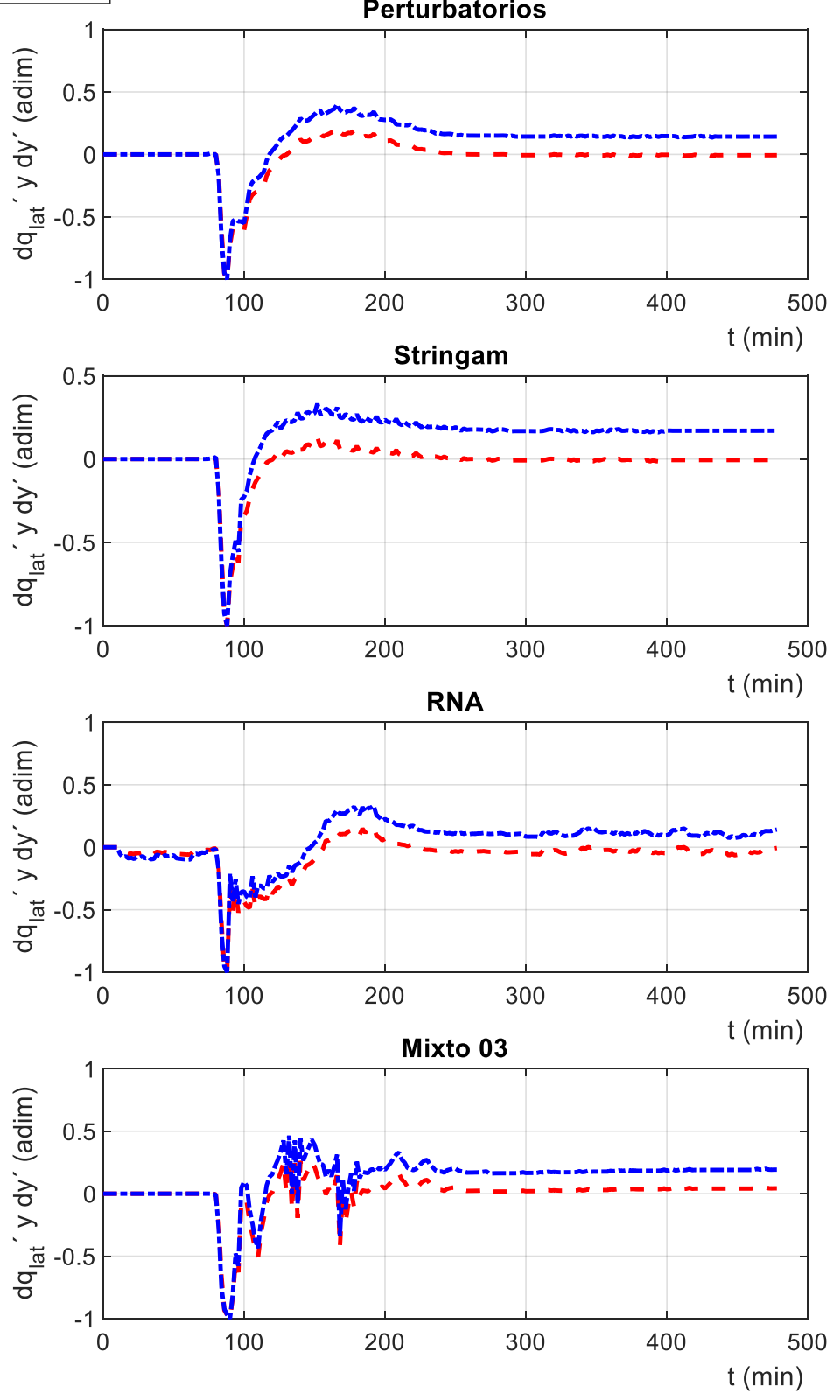

Figura 7. Errores normalizados del gasto y nivel de operación en la toma lateral $\mathrm{B}$, con respecto al máximo error $\left(x^{\prime}=\left(x^{n}-x^{0}\right) /\right.$

$$
\text { máx } \left.\left(\left|x^{n}-x^{0}\right|\right)\right) \text {. }
$$


2022, Instituto Mexicano de Tecnología del Agua Ciencias $\stackrel{\text { Tecnolóa }}{\text { Ciena }}$ Open Access bajo la licencia CC BY-NC-SA 4.0 (https://creativecommons.org/licenses/by-nc$\mathrm{sa} / 4.0 /)$

Mientras tanto, en las compuertas del canal principal la operación se hace de acuerdo con los algoritmos de control antes mencionados.

En la Figura 8 se muestran los resultados en gasto y tirante sobre el canal principal (punto $\mathrm{C}$ ), tras aplicar los algoritmos de control. En la compuerta C, a excepción del control por retardos, la descarga depende directamente de la apertura de compuerta. En el algoritmo de control mixto 2, el hidrograma de entrada al canal se fue calculando de acuerdo con los balances de masa ejecutados cada 30 minutos durante la simulación. 
Tecnología y

Ciencias $\stackrel{\Xi}{\simeq}$ gua

2022, Instituto Mexicano de Tecnología del Agua Open Access bajo la licencia CC BY-NC-SA 4.0 (https://creativecommons.org/licenses/by-ncsa/4.0/)
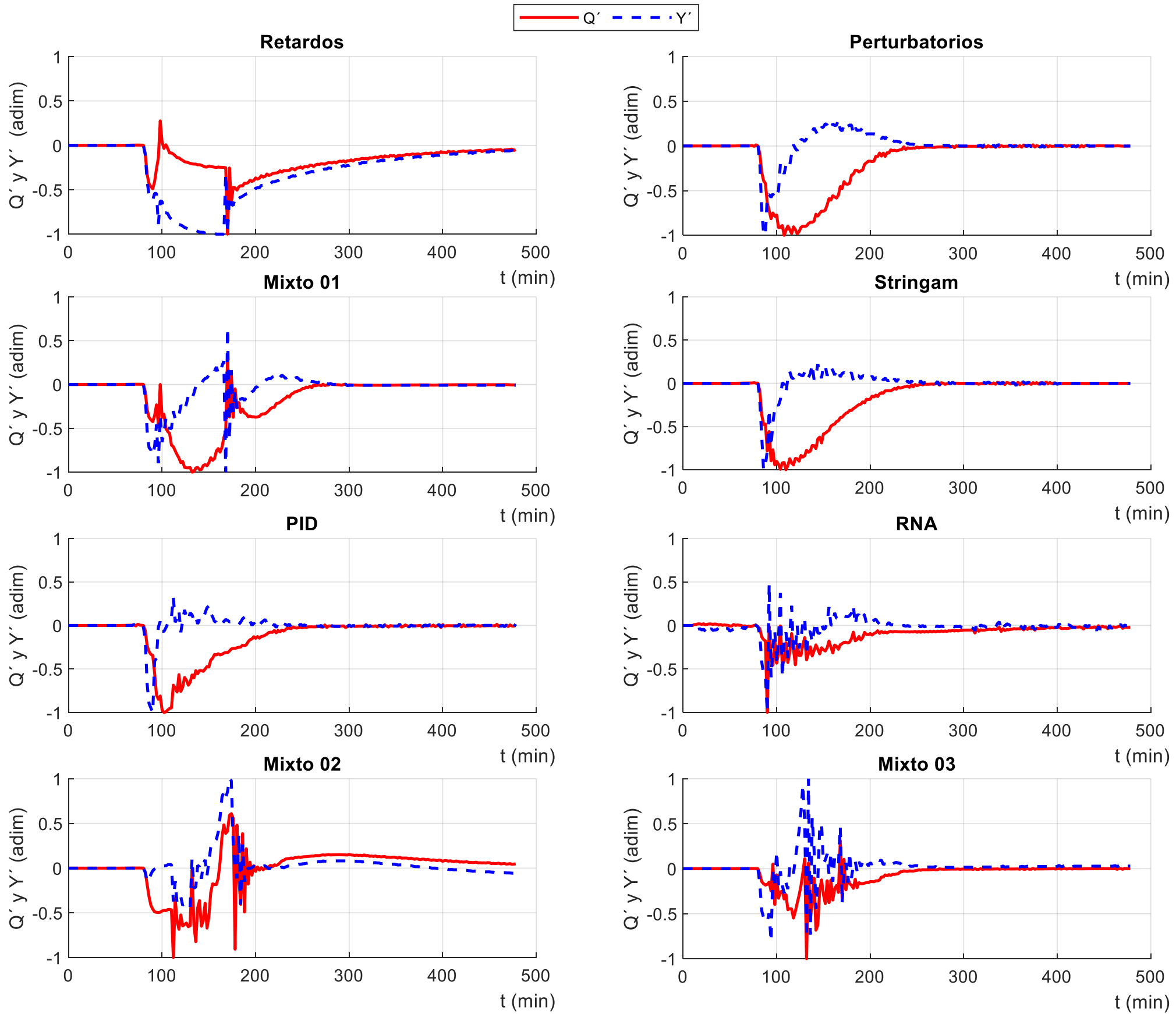

Figura 8. Errores normalizados del gasto y nivel de operación en la compuerta C. $Q^{\prime}$ y $Y^{\prime}$ son las variaciones normalizadas del gasto descargado por la compuerta C y del tirante de operación. 
2022, Instituto Mexicano de Tecnología del Agua

Tecnología y

Ciencias $\stackrel{\Xi}{\triangleleft}$ Agua
Open Access bajo la licencia CC BY-NC-SA 4.0 (https://creativecommons.org/licenses/by-nc$\mathrm{sa} / 4.0 /)$

\section{Discusión}

Al comparar los indicadores de desempeño de los algoritmos de control de la Tabla 7 con los reportados por Clemmens et al. (1998), se observa que el desempeño de los algoritmos de control sobre el canal principal (ver Figura 8) están dentro de los valores reportados en la literatura: $\mathrm{IAE} \approx 0.60 \%$ y $\mathrm{MAE}=[2.2-2.5] \%$.

Tabla 7. Indicadores de desempeño de la toma lateral (B km 32+00).

\begin{tabular}{|l|c|c|c|}
\hline \multicolumn{1}{|c|}{ Método } & MAE & IAE & Dy \\
\hline Retardos & \% & \% & M \\
\hline Perturbatorio & 3.52 & 0.24 & 0.15 \\
\hline Mixto1 (R+P) & 1.95 & 0.08 & 0.08 \\
\hline Stringam & 2.04 & 0.08 & 0.09 \\
\hline PID & 1.65 & 0.07 & 0.07 \\
\hline RNA & 2.07 & 0.07 & 0.09 \\
\hline Mixto2 (B+P) & 1.96 & 0.07 & 0.08 \\
\hline
\end{tabular}


2022, Instituto Mexicano de Tecnología del Agua

Tecnología y

Ciencias $\stackrel{\unlhd}{\unlhd}$ gua
Open Access bajo la licencia CC BY-NC-SA 4.0 (https://creativecommons.org/licenses/by-nc$\mathrm{sa} / 4.0 /)$

Mixto3 (R+PID)

2.04

0.09

0.09

En la Figura 6 y Figura 8 se observa que la respuesta de control de gasto y nivel de los algoritmos de control local (perturbatorios, Stringam, PID y RNA) es más rápida y estable, tal y como lo indica el IAE $\approx 0.07 \%$. Los métodos de control local, excepto por el de RNA, consiguieron pérdidas netas menores de US\$13.00 (ver Tabla 8). El método de Stringam y el de PID tuvieron pérdidas netas de US\$9.5; no es coincidencia que estos métodos tengan resultados tan parecidos, ya que de acuerdo con Stringam y Walh (2015), su método es una simplificación del PID. Sin embargo, el método de Stringam puede ser ejecutado ante un control manual y el PID es para un control totalmente automático.

Tabla 8. Evaluación de pérdidas en toma lateral B (DR 076 del Carrizo).

\begin{tabular}{|l|c|c|c|c|c|c|c|}
\hline \multicolumn{1}{|c|}{ Métodos } & \multicolumn{2}{|c|}{$\begin{array}{c}\text { Volumen en } \\
\text { exceso }\end{array}$} & \multicolumn{2}{c|}{$\begin{array}{c}\text { Volumen } \\
\text { faltante }\end{array}$} & $\begin{array}{c}\text { Excedentes } \\
\text { (operación) }\end{array}$ & $\begin{array}{c}\text { Faltantes } \\
\text { (sombra) }\end{array}$ & $\begin{array}{c}\text { Pérdidas } \\
\text { netas }\end{array}$ \\
\hline & $\mathbf{m}^{\mathbf{3}}$ & $\mathbf{\%}$ & $\mathbf{m}^{\mathbf{3}}$ & $\mathbf{\%}$ & $\mathbf{U S \$}$ & US\$ & US\$ \\
\hline Retardos & 0 & 0.00 & 3765 & 0.63 & 0.0 & 199.6 & 199.6 \\
\hline Perturbatorio & 180 & 0.03 & 290 & 0.05 & 2.5 & 15.4 & 12.9 \\
\hline Mixto1 (R+P) & 97 & 0.02 & 635 & 0.11 & 1.4 & 33.6 & 32.3 \\
\hline Stringam & 78 & 0.01 & 198 & 0.03 & 1.1 & 10.5 & 9.4 \\
\hline PID & 68 & 0.01 & 197 & 0.03 & 1.0 & 10.4 & 9.5 \\
\hline RNA & 80 & 0.01 & 561 & 0.09 & 1.1 & 29.7 & 28.6 \\
\hline Mixto2 (B+P) & 776 & 0.13 & 694 & 0.12 & 10.9 & 36.8 & 25.9 \\
\hline
\end{tabular}


2022, Instituto Mexicano de Tecnología del Agua

Tecnología y Open Access bajo la licencia CC BY-NC-SA 4.0 (https://creativecommons.org/licenses/by-nc$\mathrm{sa} / 4.0 /)$

\begin{tabular}{|l|c|c|c|c|c|c|c|}
\hline Mixto3 (R+PID) & 273 & 0.05 & 288 & 0.05 & 3.8 & 15.3 & 11.4 \\
\hline Esperado & & & & & & \\
\hline
\end{tabular}

Del modelo de RNA se esperaban mejores resultados, ya que en su planteamiento se incluyen como entradas los errores tanto en tirante como en gastos. Sin embrago, la calidad del RNA depende mucho de la calidad de los datos de entrena miento, que en este caso se generaron con otro modelo numérico, lo que pudo ocasionar que se arrastraran errores . Esto se podría haber evitado utilizando datos de mediciones directas en campo. A pesar de los inconvenientes, las pérdidas netas calculadas con el RNA son mucho menores al método de retardos.

Mientras el control por retardos es el método que genera mayores pérdidas en la toma B (US\$199.6), muestra buen desempeño sobre el canal principal (porcentaje de errores de operación menores al $5 \%$ (Luján, 1991) debido a que está diseñado para entregar en tiempo los gastos sobre el canal principal, precisamente, y no en las tomas laterales.

De manera general se logra apreciar que los modelos de control automáticos garantizan una entrega más uniforme en comparación con la operación manual. Sin embargo, en la prueba del control mixto 3 se muestra una mejora al tradicional control por retardos, que va de $\$ 199.6$ a $\$ 11.5$ en pérdidas netas en el volumen de agua. A pesar de que esta estrategia de control genera mayores pérdidas que el control totalmente automático PID, así como el control MoMPC propuesto por Van-Overloop et al. (2014), esta estrategia sigue involucrando al ser humano en el ciclo del control, lo que se asocia con una mejor vigilancia de los equipos de control. 


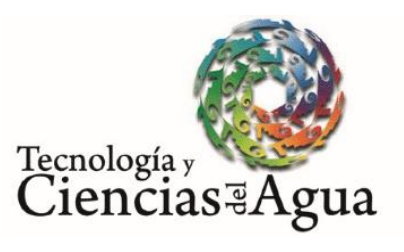

2022, Instituto Mexicano de Tecnología del Agua

Open Access bajo la licencia CC BY-NC-SA 4.0 (https://creativecommons.org/licenses/by-nc$\mathrm{sa} / 4.0 /)$

\section{Evaluación económica del control manual}

El volumen faltante en la operación manual (retardos) representa menos de $1 \%$ del volumen requerido en la toma lateral, pero en términos económicos son US\$199.5 de pérdidas en volumen de agua. Si se considera la productividad del agua en la zona (Tabla 3), se puede decir que en esta zona se han dejado de producir US\$1 135.00 en maíz. Se toma como ejemplo el maíz porque es el cultivo sembrado en mayor superficie en la zona de riego, después del trigo, que se ha descartado como parámetro de la productividad por su resistencia al estrés hídrico.

Como ya se mencionó, la mejor forma de mejorar el control por retardos sin sacar del todo al ser humano fue, en este caso, combinar con el control PID. En esta prueba, los volúmenes faltantes y en exceso habrían generado una pérdida máxima de US\$0.26 x $\left(288 \mathrm{~m}^{3}+273 \mathrm{~m}^{3}\right)$ $=$ US\$145.9. Con la operación manual basada en el cálculo de los retardos se obtuvo una eficiencia de $97.8 \%$, lo que indica que la operación manual no debería estar directamente relacionada con eficiencias menores al 90 $\%$. Luego, los puntos a cuidar de la operación manual serían identificar muy bien el canal y la puntualidad tanto de los operadores como de los usuarios, tal y como lo mencionan Luján (1991), Pedroza e Hinojosa (2014), y García (2015). 


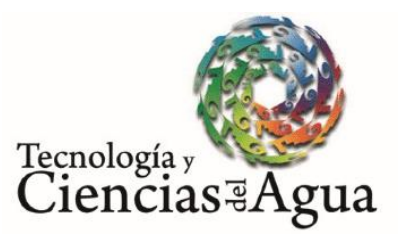

2022, Instituto Mexicano de Tecnología del Agua

Open Access bajo la licencia CC BY-NC-SA 4.0 (https://creativecommons.org/licenses/by-nc$\mathrm{sa} / 4.0 /)$

\section{Conclusión}

A partir del escenario evaluado aplicando los diferentes algoritmos de control, se observó que los controles Stringam y PID logran mantener el nivel dentro del margen $\Delta y<0.10 \mathrm{~cm}$ y tienen un desempeño de $\mathrm{IAE}=$ $0.07 \%$. También se observa que no hay cambios en el gasto en la compuerta de la descarga lateral. Sin embargo, hacia aguas abajo del canal, debido a que se quiere mantener el control al final del tramo, se generan variaciones en la descarga hacia el punto $C$. De igual forma, se evaluaron las ventajas de aplicarcontroles automáticos no tan complejos, pero con fundamentos sólidos como el de Stringam (Stringam \& Wahl, 2015) de perturbaciones, como el que se presenta en el anexo A. Se observa que con los modelos de control automáticos mejora la uniformidad en las entregas de los volúmenes de agua, e incluso cuando se combinan con controles locales automáticos con un control global manual.

El agua es un bien insustituible y asignarle un precio a los errores en la operación permite incrementar el interés de los usuarios del agua en mejorar la eficiencia desde la conducción. Preciar el agua ante cada algoritmo de control busca sensibilizar sobre el uso del agua como un bien por el que no se paga, pero que contribuye a mejorar la planeación desde 
2022, Instituto Mexicano de Tecnología del Agua $\mathrm{sa} / 4.0 /$ )

una visión integrada de cuenca (Turner, Georgiou, Clark, \& Brouwer, 2004).

En este artículo no se sugiere de ninguna forma que el agua deba ser cobrada o vista como bien económico, simplemente se da a conocer un valor estimado del agua en la producción agrícola, y se exploran algunos escenarios para mejorar su uso y aprovechamiento. Los resultados obtenidos pueden servir para que los usuarios consideren los beneficios de modernizar su infraestructura hidráulica $y$, en forma paralela, disminuir los volúmenes de aprovechamiento, con el fin de contribuir a un mejor cuidado del recurso natural hídrico.

\section{Agradecimientos}

Los autores expresan su agradecimiento a la Universidad Nacional Autónoma de México (UNAM), al Instituto Mexicano de Tecnología del Agua (IMTA), al Consejo Nacional de Ciencia y Tecnología (Conacyt) y a todos los que contribuyeron al desarrollo de este estudio. 
2022, Instituto Mexicano de Tecnología del Agua

Open Access bajo la licencia CC BY-NC-SA 4.0 (https://creativecommons.org/licenses/by-nc$\mathrm{sa} / 4.0 /$ )

\section{ANEXO A. Controlador derivado por métodos perturbatorios}

Sea la ecuación de la descarga de una compuerta $F_{1}=\frac{Q}{C_{d} b \sqrt{2 g}}$, se considera como objetivo mantener constantes en el tiempo el nivel de operación $\bar{y}_{r}$ y un gasto de descarga $Q$ conocido. Solamente la apertura $w(t)$, tirante aguas abajo $y_{3}(t)$ y tirante aguas arriba $y_{r}(t)$ son valores dinámicos del sistema:

$Q=C d w b \sqrt{2 g\left(y_{r}-y_{3}\right)}$

Si se despeja la apertura de la compuerta de la Ecuación (A.1) y se agrupan los términos considerados como invariantes $F_{1}=\frac{Q}{C_{d} b \sqrt{2 g}}$, para el caso en que se desea mantener constante la extracción, las variaciones en la apertura del canal son una función que depende del tirante observado aguas arriba y debajo de la compuerta:

$w\left(y_{r}, y_{3} ; t\right)=f\left(y_{r}, y_{3} ; t\right)=F_{1}\left(y_{r}-y_{3}(t)\right)^{-\frac{1}{2}}$ 
2022, Instituto Mexicano de Tecnología del Agua

Tecnología y

Ciencias $₫$ Agua
Open Access bajo la licencia CC BY-NC-SA 4.0 (https://creativecommons.org/licenses/by-ncsa/4.0/)

El modelo dinámico de la ecuación anterior se puede descomponer en dos escalas: una sobre el nivel objetivo o nivel a controlar $\bar{y}_{r}$, y una variación o perturbación $y_{r}^{\prime}$, y se dice que $\bar{y}_{r} \gg\left|y_{r}^{\prime}\right|$ (ver Figura 1.A). Con lo anterior se puede considerar la separación de escalas $y_{r}=\bar{y}_{r}+y_{r}^{\prime}$, es decir, una de baja y una de más alta frecuencia. Aplicando esta separación de escalas a la Ecuación (A.2), tal que $w\left(y_{r}\right)=w\left(\bar{y}_{r}+y_{r}^{\prime}\right)$ para determinar las diferentes escalas sobre la función de apertura de la compuerta se propone aplicar una serie de Fréchet-Taylor (Milne, 1980), entonces se tiene:

$w\left(y_{r}\right)=w\left(\bar{y}_{r}\right)+\left.y_{r}^{\prime} \frac{\partial w}{\partial y_{r}}\right|_{\bar{y}_{r}}+\left.\frac{y_{r}^{\prime 2}}{2 !} \frac{\partial^{2} w}{\partial y_{r}^{2}}\right|_{\bar{y}_{r}}+\cdots$

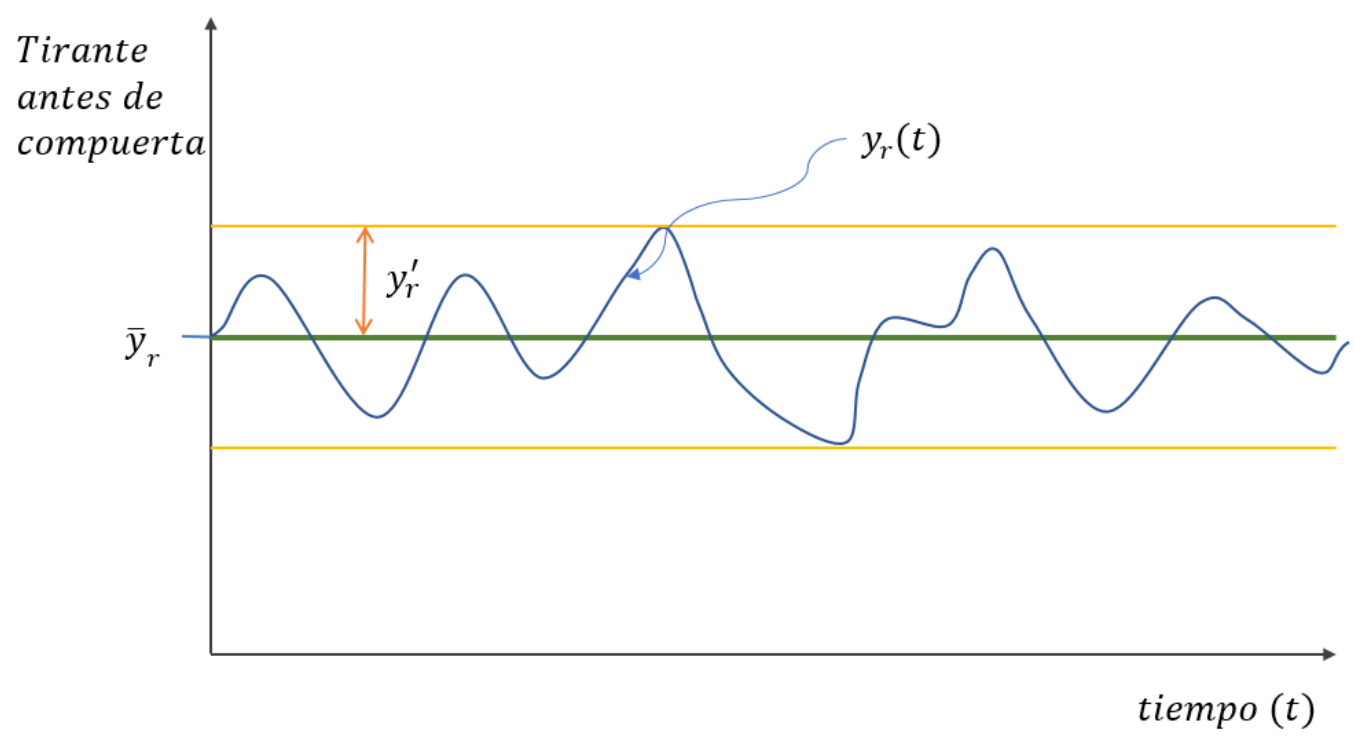

Figura A1. Variaciones del tirante arriba de la compuerta. 
Los cambios en la apertura de compuerta son $\Delta w=w\left(y_{r}\right)-w\left(\bar{y}_{r}\right)$. Además, las derivadas son términos que incorporan los efectos de sensibilidad de la apertura sobre el nivel, para lo que $K_{p_{1}}=\left.\frac{\partial w}{\partial y_{r}}\right|_{\bar{y}_{r}}=-\frac{1}{2} F_{1}$. $\left(y_{r}-y_{3}\right)^{-1.5}$ y $K_{p_{2}}=\left.\frac{1}{2 !} \frac{\partial^{2} w}{\partial y_{r}^{2}}\right|_{\bar{y}_{r}}=\frac{3}{8} F_{1} \cdot\left(y_{r}-y_{3}\right)^{-2.5}$. Finalmente, el control de perturbaciones para dirigir la apertura de la compuerta queda como:

$$
w^{n+1}=w^{n}+y_{r}^{\prime} K_{p_{1}}+y_{r}^{\prime 2} K_{p_{2}}
$$

Este algoritmo requiere que se defina el intervalo de tiempo para el que se calculará la nueva acción de control $\left(T_{\text {control }}\right)$ y además se debe establecer la velocidad con que la compuerta puede ejecutar una maniobra $\left(T_{\text {maniobra }}\right)$. Al aplicar este algoritmo, se observó que se pueden suavizar las perturbaciones al utilizar una fracción de la derivada $K_{p_{1}}$, a la cual se le denominó $K_{L}$, y modificando el modelo como $w^{n+1}=w^{n}+K_{L} K_{p_{1}} y_{r}^{\prime}$.

\section{Referencias}

Abbot, M. (1979). Computational hydraulics: Element of the theory of free surface flows. London, UK: Pitman Publishing Limited.

Aguilar-Chávez, A., Pedroza-González, E., Kosuth, P., \& Daval, E. (1994). Automatización de un canal de riego. Canal Alto del distrito de Riego del río Yaqui. En: El agua ante el siglo XXI, 6. 
2022, Instituto Mexicano de Tecnología del Agua

Tecnología y

Ciencias $\stackrel{\Xi}{\Im}$ Agua
Open Access bajo la licencia CC BY-NC-SA 4.0 (https://creativecommons.org/licenses/by-nc$\mathrm{sa} / 4.0 /)$

Aldama, A., \& Aguilar, A. (1996). Stability analysis of a general Preissmann scheme. Computational Methods in Water Resources, $11,11,37-44$.

Álvarez, A., Ridao, M. A., Ramírez, D., \& Sánchez, L. (2013). Constrained predictive control of an irrigation canal. Journal of Irrigation and Drainage, 139(10), 841-854.

Astrom, K., \& Murray, R. (2008). Feedback systems. Princeton, USA: Princeton University Press.

Bierkens, M. F., Reinhard, S., De-Brujin, J. A., Veninga, W., \& Wada, Y. (25 de mayo, 2019). The shadow price of irrigation water in major groundwater-depleting countries. Water Resources Research, 55, 4266-4287.

Chaudhry, M. H. (2008). Open channel flow. Columbia, USA: Springer.

Clemmens, A. J., Kacerek, T., Grawitz, B., \& Schuurmans, W. (1998). Test cases for canal control algorithms. Journal of Irrigation and Drainage Engineering, 124(1): 23-30.

Clemmens, A., Sloan, G., \& Schuurmans, J. (1994). Canal-control needs: Example. Journal of Irrigation and Drainage Engineering, 120(6), 1067-1085.

Conagua, Comisión Nacional del Agua. (2018). Estadísticas agrícolas de los distritos de riego. Año agrícola 2016-2017. Ciudad de México, México: Secretaría del Medio Ambiente y Recursos Naturales.

Cruz-Mayo, P., Aguilar-Chavez, A., \& De-la-Torre, C. D. (2019). Transient flow simulation in irrigation channels. En: IAHR (ed.). E-proceedings of the 38th IAHR World Congress (pp. 5476-5485). Panamá, 
2022, Instituto Mexicano de Tecnología del Agua

Tecnología y

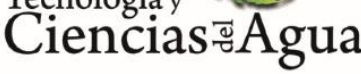

Open Access bajo la licencia CC BY-NC-SA 4.0 (https://creativecommons.org/licenses/by-nc$\mathrm{sa} / 4.0 /)$

Panamá: International Association for Hydro-Environment Engineering and Research.

Ley Federal de Derechos. (1981). Capítulo VIII Agua. Diario Oficial de la Federación. Recuperado de http://www.diputados.gob.mx/LeyesBiblio/pdf_mov/Ley_Federal_ de_Derechos.pdf

Durdu, O. F. (2004). Optimal control of irrigation canals using recurrent dynamic neural network (RDNN). In: World Water and Environmental Resources Congress. Salt Lake City, USA: American Society of Civil Engineers. http:\\doi.org/10.1061/40737(2004)223

García, N. H. (2015). Operación de canales. Conceptos generales. Jiutepec, México: Instituto Mexicano de Tecnología del Agua.

González-Trinidad, J., León-Mojarro, B. D., Carmona-Ruiz, V., \& RendónPimentel, L. (1999). Sistema de regulación de canales en el distrito de riego de la Begoña, Guanajuato. Ingeniería Hidráulica en México, $14(2), 11-20$

Hashemy, S. M., \& Roozbhani, A. (2015). Selecting an appropriate operational method for main irrigation canals within multicriteria decision-making methods. Journal of Irrigation and Drainage Engineering. DOI: 10.1061/(ASCE)IR.1943-4774.0000996

Hashemy, S. M., Hasani, Y., Majidi, Y., \& Maestre, J. M. (2016). Modern operation of Maing irrigation canals suffering water scarcity based on an economic perspective. Journal of Irrigation and Drainage 
2022, Instituto Mexicano de Tecnología del Agua

Tecnología y

Ciencias $\stackrel{\Xi}{\Im}$ Agua
Open Access bajo la licencia CC BY-NC-SA 4.0 (https://creativecommons.org/licenses/by-nc$\mathrm{sa} / 4.0 /)$

Engineering. 143(3): B4016001. DOI: 10.1061/(ASCE)IR.19434774

Hassani, Y., Hashemy, S. M., Maestre, J., Zahraie, B., Ghorbanif, M., Rastegari H., S., \& Kulshreshtha, S. N. (2019). An economicoperational framework for optimum agricultural water distribution in irrigation districts without water marketing. Agricultural Water Management. 221, 348-361.

Haykin, S. (2010). Neural networks and learning machines. India: Pearson Education. Pearson Education India.

Hernández, Y., Feliu, V., \& Rivas, R. (2017). Artificial neural network based system identification of an irrigation main. IEEE Latin America Transactions, 15(9), 1595-1600.

Luján, J. (1991). Eficiencia del riego. Madrid, España: Centro de Estudios y Experimentacion de Obras Públicas.

Malaterre, P. O. (2007). Control of irrigation canals: Why and how? In:

Playan, G. N. (ed.). International Workshop on Numerical Modelling of Hydrodynamics for Water Resources (pp. 271-292). Zaragoza, España: Taylor and Francis (Balkema Ed.).

Milne, R. (1980). Applied functional analysis. An introduction treatment. Londres, UK: Pitman Publishing Limited.

Mohapatra, A. G., \& Lenka, S. K. (2016). Neural network pattem classification and weather dependent fuzzy logic model for irrigation control in WSN based precision agriculture. Procedia Computer Science, 78, 499-506. 
2022, Instituto Mexicano de Tecnología del Agua

Tecnología y

Ciencias $\stackrel{\Xi}{\Im}$ Agua
Open Access bajo la licencia CC BY-NC-SA 4.0 (https://creativecommons.org/licenses/by-nc$\mathrm{sa} / 4.0 /)$

Norton, R. G. (2004). Política de desarrollo agrícola. Conceptos y principios. Roma, Italia: Organización de las Naciones Unidas para la Alimentación y la Agricultura.

Nunes-da-Silva, I., Hernane-Spatti, D., Andrade-Flauzino, R., \& BartocciLiboni, L. H. (2017). Artificial Neural Networks. A practical course. Springer. São Paulo, Brazil. DOI 10.1007/978-3-319-43162-8

Pedroza, E., \& Hinojosa, G. (2014). Manejo y distribución del agua en distritos de riego. Breve introducción didáctica. Jiutepec, México: Instituto Mexicano de Tecnología del Agua.

Ramírez, D. R. (7 de diciembre, 2018). Comunicación personal.

Ruslan, F. A. (2014). Flood water level modeling and prediction using NARX neural network: Case study at Kelang river. In: 2014 IEEE 10th International Colloquium on Signal Processing and its Applications (pp. 204-207). IEEE. Kuala Lumpur, Malaysia.

Secretaría de Economía. (octubre, 2019). SNIIM. Recuperado de http://www.secofi-sniim.gob.mx

Stringam, B. L., \& Wahl, T. L. (2015). The ratio controller for regulation of turnout flow rate. Irrigation and Drainage. 64(1), 69-76. DOI: 10.1002/ird. 1881

Swamee, P. K. (28 de enero, 1992). Sluice-Gate discharge equations. Journal of Irrigation and Drainage, 118(1), 56-60.

The Mathworks, I. N. (2019). MATLAB. Massachusetts, USA: The Mathworks, I. N. 
2022, Instituto Mexicano de Tecnología del Agua

Tecnología y

Ciencias $\stackrel{\unlhd}{\triangleleft}$ gua
Open Access bajo la licencia CC BY-NC-SA 4.0 (https://creativecommons.org/licenses/by-nc$\mathrm{sa} / 4.0 /)$

Torres-Sombra, J., \& García S., J. (2015). Uso del agua en el norte de Sinaloa: ¿a cuál consumidor asignar el recurso? Tecnología y ciencias del agua, 6(1), 167-173.

Turner, K., Georgiou, S., Clark, R., \& Brouwer, R. (2004). Economic valuation of water resources in agriculture. From the sectorial to a functional perspective of natural resource management. Rome, Italy: Food and Agriculture Organization.

Van-Overloop, P. J., Maestre, J., Hashemy, S., Sadowska, A. D., Davids, J., \& Camacho, E. (2014). Human in the loop control of Dez Main Canal. In: Planning, Operation and Automation of Irrigation Delivery Systems (pp. 307-319). Phoenix, USA: American Society of Civil Engineers.

Zetina-Espinosa, A. M., Mora-Flores, J. S., Martínez-Damián, M. A., CruzJiménez, J., \& Téllez-Delgado, R. (2013). Economic value of water in Irrigation District 044, Jilotepec, Estado de México. Agricultura, Sociedad y Desarrollo, 10(2), 139-156. 